\title{
Commercial utilities and future perspective of nanomedicines
}

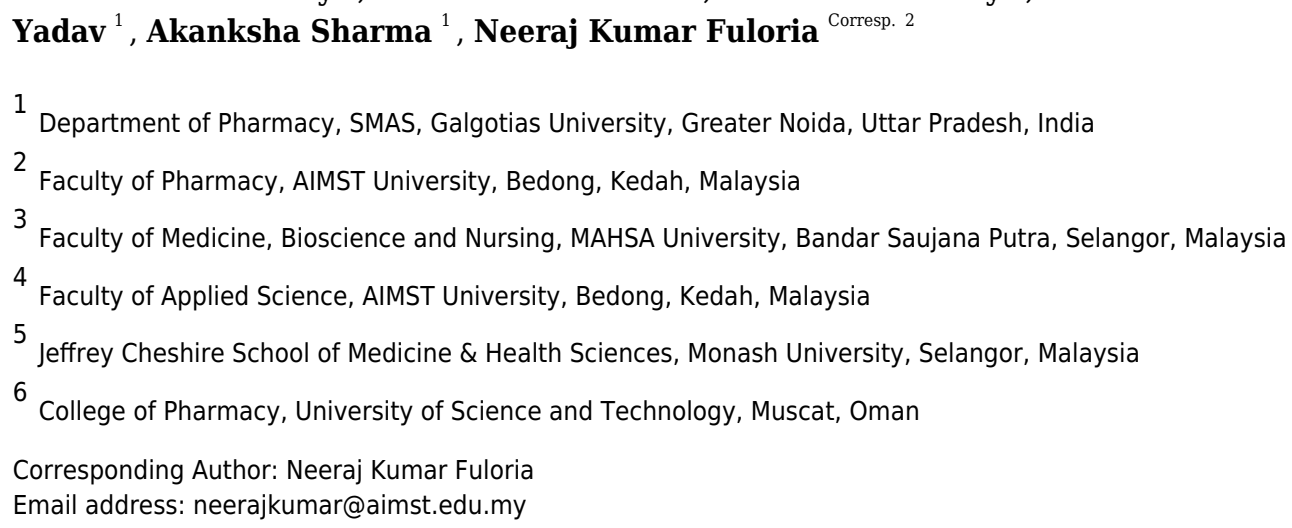

The present review aims to describe the commercial utilities and future perspectives of nanomedicines. Nanomedicines are intended to increase precision medicine and decrease the adverse effects on the patient. Nanomedicines are produced, engineered, and industrialized at the cellular, chemical, and macromolecular levels. This study describes the various aspects of nanomedicine such as governing outlooks over high use of nanomedicine, regulatory advancements for nanomedicines, standards, and guidelines for nanomedicines as per Therapeutic Goods Administration (TGA). This review also focuses on the patents and clinical trials based on nanoformulation, along with nanomedicines utilization as drug therapy and their market value. The present study concludes that nanomedicines are of high importance in biomedical and pharmaceutical production and offer better therapeutic effects especially in the case of drugs that possess low aqueous solubility. The factual data presented in this study will assist the researchers and health care professionals in understanding the applications of nanomedicine for better diagnosis and effective treatment of a disease. 


\section{Commercial utilities and future perspective of}

\section{2 nanomedicines}

3

4

5

6

7

Rishabha Malviya ${ }^{1}$, Shivkanya Fuloria ${ }^{2}$, Swati Verma ${ }^{1}$, Vetriselvan Subramaniyan ${ }^{3}$, Kathiresan Sathasivam ${ }^{4}$, Vinoth Kumarasamy ${ }^{3}$, Darnal Hari Kumar ${ }^{5}$, Shalini Vellasamy ${ }^{3}$, Dhanalekshmi Unnikrishnan Meenakshi ${ }^{6}$, Shikha Yadav ${ }^{1}$, Akanksha Sharma ${ }^{1}$ and Neeraj Kumar Fuloria ${ }^{2 *}$

${ }^{1}$ Department of Pharmacy, SMAS, Galgotias University, Greater Noida, Gautam Budha Nagar 201310, India

${ }^{2}$ Faculty of Pharmacy, AIMST University, Kedah 08100, Malaysia

${ }^{3}$ Faculty of Medicine, Bioscience and Nursing, MAHSA University, Jalan SP 2, Bandar Saujana Putra, 42610 Jenjarom Selangor, Malaysia

${ }^{4}$ Faculty of Applied Science, AIMST University, Kedah, Bedong 08100, Malaysia

${ }^{5}$ Jeffrey Cheshire School of Medicine \& Health Sciences, Monash University, Selangor 47500Malaysia

${ }^{6}$ College of Pharmacy, University of Science and Technology, Muscat 130, Oman

Corresponding Author:

Neeraj Kumar Fuloria ${ }^{2}$

Faculty of Pharmacy, AIMST University, Kedah 08100, Malaysia

Email address: neerajkumar@aimst.edu.my

\section{Rationale}

Several medicinally important drugs despite of their high therapeutic potential using get failed owing to their low solubility, permeability, specificity and adverse effects. The nanomedicines are gains high importance in pharmaceuticals and biomedical field, as improvises the pharmacokinetic properties of drugs, higher safety, and better therapeutic efficacy. So, it becomes essential to understand the various aspects of nanomedicine, such as governing outlooks over high use of nanomedicine, regulatory advancements for nanomedicines, standards, and guidelines. The facts presented in this study will assist the health professionals and researchers to apply the nanomedicines for an effective treatment.

\section{Target Readers}

The concept of nanomedicines presented in this review will cover a larger number of readers belonging to various fields of science such as: biomedical science, pharmacy, material science, and biotechnology.

\section{Survey Methodology}

Data presented in this review were collected using various search engines such as: PubMed, Google Scholar, and SciFinder. Terms used to find the data included nanomedicines, patents, 
39 TGA, Guidelines, therapy, and disease etc. The majority of data covered in this study was selected 40 from last five years, but some important data until last 20 years were also covered.

\section{Abstract}

42 The Present review aims to describe the commercial utilities and future perspectives of 43 nanomedicines. Nanomedicines are intended to increase precision medicine and decrease the 44 adverse effects on the patient. Nanomedicines are produced, engineered, and industrialized at the cellular, chemical, and macromolecular levels. This study describes the various aspects of nanomedicine such as governing outlooks over high use of nanomedicine, regulatory advancements for nanomedicines, standards, and guidelines for nanomedicines as per Therapeutic Goods Administration (TGA). This review also focuses on the patents and clinical trials based on nanoformulation, along with nanomedicines utilization as drug therapy and their market value. The present study concludes that nanomedicines are of high importance in biomedical and pharmaceutical production and offer better therapeutic effects especially in the case of drugs that possess low aqueous solubility. The factual data presented in this study will assist the researchers and health care professionals in understanding the applications of nanomedicine for better diagnosis and effective treatment of a disease.

Keywords: Nanomedicines, Nanotechnology, Drug Therapy, Nanoparticles, Disease Treatment

\section{Introduction}

Over the past two decades, several studies explored and heralded nanotechnology as a "modern

59

60

61

62

63

64

65

66

67

68

69

70

71

72

73

74

75

76

77

78 scientific breakthrough. The field allows for interconnected platforms based on solutions to unmet needs and problems in a variety of areas such as physics, chemistry, biotechnology, engineering, and especially in medical sciences; providing a range of possibilities in a variety of traditional research areas specifically in areas of medical sciences (Navalakhe \& Nandedkar, 2018). Nanotechnology is gaining specific popularity in many of these fields as an important scientific method for addressing major problems such as enhanced and precise medicine, reduced adverse effects/no toxicity risks, and meeting previously unmet patient needs in a suitable manner (Shrivastava \& Dash, 2009). Nanomedicines have been engineered, produced, and industrialized at the chemical, cellular, and macromolecular levels in recent decades. The area of nanomedicine, which includes nanopharmaceuticals, nanoimaging agents, and theranostics, has resulted in increased creativity and significant advancements in disease detection, tomography, prevention, and care (Shrivastava \& Dash, 2009; Sahoo et al., 2006).

The rapid development of novel nanomedicines has shown potential in terms of enhancing public health and quality of life. Nanomedicines' nanoscale size (1-100 nm) and large surface area offer appropriate platforms for accessing biological targets and interacting with cells and tissues in a highly precise manner (Sahoo et al., 2006). Increased funding and the effective implementation of multidisciplinary technologies in academia and industry have resulted in more advanced, dependable, and novel nanomedicines like polymer-conjugates, nanoparticles (Lipidic and Polymeric both), and liposomes. A list of marketed nanoformulations is represented in (Table 1). These may lead to a variety of strategies, which are primarily supported by: (a) the utility of new fabrication processes, materials, and techniques (e.g., surface/chemical modifications to 
overwhelmed concerns related to the stability of formulation and/or targeting ligands to cellular membranes or even organelles present inside the membrane); (b) the formulation in nano-scale size (Chitrani et al., 2006) which allows it to surpass through some major physiological obstacles, resulting in potent drug targeting; (c) the entrapment of necessary volumes of medicaments of various nature while shielding them from hostile setting, and achieving availability of medicament at the required site in required concentration without impacting the co-existing healthy tissue while improving their toxicity profile (Gaspar et al., 2014).

Though a significant demand for supporting these nanomedicines, their unique properties have presented significant obstacles to industry and regulatory agencies. Furthermore, there has been a shortage of novel design criteria, precise procedures, and groundbreaking methods to classify these nanomedicines at clinical, physicochemical, and biological stages, which could have contributed to the failure in late-stage trials in a variety of instances (Soares et al., 2018). Therefore, key issues have progressively challenged the regulatory system for these revolutionary nanomedicines, to create a break to clear the guidance associated with their development.

\section{Governing Outlooks on Enhancement of Nanomedicine}

In recent decades, there have been several licensed nanomedicines having multi-dimensional applications in the biomedical field, but the lack of novel design criteria, precise procedures, and groundbreaking methods related to production at preclinical stages and depiction of these nanomedicines have hindered their probability related to further advancement in clinical fields (Allen \& Cullis, 2013). Despite the attempts that have already been made; global regulatory developments must be established. Even though several significant measures have already been implemented over the last five years, strong cooperation between regulatory authorities/bodies is still required. Instead, the methods used currently to produce medicinal products having traditional background have been altered to assess the compatibility and the safety profile of experimental nanomedicines (Dorbeck \& Chawdhury, 2011). According to the regulator, the conditions associated with the API of nanodrugs should be specified within the regulatory structure. Biological entities are subject to the same restrictions like proteins, peptides, and antibodies that come with new chemical entities (NCEs) and potential therapeutic active drugs (Gaspar, 2010). In general, a constraint to the management of these nanomedicines is directly related to their special properties. The advancements discussed for lipid nanoparticles, cubosomes, and other polymeric structures (including micelles), indicate that the therapeutic use of these more advanced and complex nanomedicines is highly dependent on flexibility. However their properties are flexible not just through slight adjustments in their raw materials, but also through minor alterations in their manufacturing processes. As a result, these changes lead to minor structural modifications in the bioactivities and bio-distribution behaviors (Gaspar \& Ducan, 2009). Besides, investigators and formulation scientists regularly link medicines and drug candidates, molecules used for targeting, as well as elements usually used for tracking and imaging to nanotherapeutics. A requirement for new quality control assays and some robust methods are for the effective monitoring and evaluation not only their physicochemical characteristics, such as size and size variability, shape, and charge but also because of their size and physical characteristics, 
119

120

121

122

123

124

125

126

127

128

129

130

131

132

133

134

135

136

137

138

139

140

141

142

143

144

145

146

147

148

149

150

151

152

153

154

155

156

157

158

nanomedicines are well known for their capacity to interact with immune cells and adsorb plasma proteins (Dobrovolskaia \& McNeil, 2007). As a consequence, biocompatibility and autoimmunity must be taken into account during the preclinical evaluation. The therapeutic efficacy and dosage regimen, as well as the administration pathway and targeted disease setting, all lead to an accurate estimation of toxicity during development. When molecules are entrapped and delivered to their specific destinations around the globe, nanomedicines have shown the potency and lower toxicity profile of conventional drugs, and also their biocompatibility (Soares et al., 2018; Allen \& Cullis, 2013). On the other hand, numerous predicted nanomedicine classes, like quantum dots, dendrimers, and carbon nanotubes, have gained recognition. However, owing to the potential toxicity profile and immunological negative impacts of these innovative drugs, the clinical aspect of these drugs could be negotiated for many years (Caminade \& Majoral, 2010).

Adapting manufacturing methods has been a new hurdle in the research, development, and medicinal translation of these nanodrugs. Due to the complex properties and reactivities of modern drugs, major production-related issues face contemporary pharmaceutical science at manufacturing plants, presenting a threat to their scale-up capability. It is important to identify and monitor important elements during each manufacturing step. Using QbD i.e., Quality by design concept, involving processes such as PAT i.e., process analytical technology (PAT), will maintain a quality measurement technique that is online/at-line (Stanczyk et al., 2007). Anticipating and comprehending some of the critical points of progress helps us in the usage of automated systems to solve hiccups when they emerge. These foresighted plans resulted in the acceptance and implementation of $\mathrm{ICH}$ guidelines Q8, Q9, and Q10 as regulations for new pharmaceutical manufacturing. Furthermore, the important consequences for current pharmaceutical products explored in this paper may pave the way for the development of new and highly efficient manufacturing processes for future nanomedicines (Merchant et al., 2009).

Companies and governmental agencies in countries like Japan, USA and Europe have traditionally worked to enact comprehensive regulatory frameworks via ICH. Nonetheless, different points of view continue to serve as the basis for many protocols implemented by the USFDA, and the EMA. A few standardized assays and methods are often needed to examine problems that have a substantial effect on the in-vivo safety/efficacy of nanotherapeutics (Bawa et al., 2008). The core complexity, however, is associated with the development of receptive assays for recognizing low doses of nanocarriers, discriminating them from modified aggregates, or from metabolized forms. Surprisingly, alternative imaging technologies, such as techniques used for cellular imaging and fluorescence, are anticipated and researched as tools for overcoming the limitations associated with it and pursuing healthcare breakthroughs. Another impediment to the regulation of these nanoproducts is the need of providing data before and during the product's life cycle, which necessitates in-vivo animal trials and therapeutic procedures (Sainz et al., 2015). The European regulatory regime allows for "scientific counseling services" from regulators to applicants for the benefit of Authorisation Applications (MAA), making for a smooth translational into clinical applications from the early stages of R\&D. By that the impact of major avoidable obstacles in the process, could contribute to more harmonized development, driven by tremendous advancements 
159 in advanced techniques of nanomedicine. This can rapidly contribute to more organized progress, 160 driven by significant developments in advanced pharmaceutical strategies that can help to 161 minimize the impact of numerous roadblocks encountered during the production process (Mitchell

162

163

164

165

166

167

168

169

170

171

172

173

174

175

176

177

178

179

180

181

182

183

184

185

186

187

188

189

190

191

192

193

194

195

196

197

198

et al., 2021). Currently, the European Medicines Agency (EMA) has established a working group for the scientific evaluation and control of medicines, with a particular emphasis on concerns concerning the safety, feasibility, and efficacy of nano-products. Furthermore, this organization has prepared papers known as "orientation notes" that address important problems that candidates in the field of nanomedicines must remember (Duncan \& Izzo, 2005). Despite the absence of detailed nanomedicine protocols, regulatory regimes in the United States (FDA), Europe (EMA), and Japan (PDMA/MHLW) have coordinated since 2009-2010 to gain large perspectives in the field of novel nanomedicine production (Bawa et al., 2008). Big pharmaceutical companies are now displaying a great deal of interest in the clinical development and "proof of concept" of these nano-systems. All these considerations would help to improve protocols for evaluating drug efficacy, targeting ability, toxicity control, and the safety of novel nanomedicine medicines (Ventola, 2012), (Oberdorster, 2009). Furthermore, pharmaco-economic studies will be needed for the demonstration of the social and economic added value of these nanomedicines over established treatments prior to commercial exploitation, and critical aspects such as a rise in quality-adjusted life expectancy years i.e., QALEYs or cost related to hospitalizations soon would also be included in the advancement of these theories (Nadeem, 2020).

\section{Regulatory Advancements for Nanomedicines of the "Next Generation"}

The regulatory environment surrounding the production and evaluation of nanomedicines has been under increased scrutiny since the organization of the International Conference on Harmonization (ICH) in the early nineties. The predicted development necessitates more and more evidence of dominance in therapeutic effectiveness from new and emerging novel methods, as well as intensified pressure for pharmaco-economic evaluation (Ehmann et al., 2013). The historic evidence of non-inferiority is no longer applicable in certain treatment contexts, but clinical recommendations for the vast majority of applications are continually reviewed and modified. Furthermore, new opportunities in healthcare administration, such as health technology assessment (HTA), emphasize the importance of incorporating a variety of treatment methods that are complementary to the therapeutic classical oncology paradigm (Patra et al., 2018). Biopharmaceutical advances in several clinical areas have often shown their inherent superiority, outperforming other nanotechnology-based approaches. It is important to remember that the bulk of the modern structures are based on substances that were new in the late 1970s as well as early 1980s but are now no longer usable, including doxorubicin and others (Gaynes, 2017). Nanosimilars, which are the combination of generic drugs and nanocarriers used as an excipient (novel) are the major sticking point in the legislative discussions. Furthermore, the discussion involving formulations that are similar and are within the non-biological complex drugs (NBCDs), revealed a slew of critical issues in specific formulations (iron oxide nanoparticles, liposomes, polymeric micelles) (Khurana et al., 2019). Both aspects are also subject to increase congressional oversight. Simultaneously, the EMA's ITF (innovation task force) had begun to gather data, and

Peer) reviewing PDF | (2021:06:61967:2:0:NEW 27 Sep 2021) 
199

200

201

202

203

204

205

206

207

208

209

210

211

212

213

214

215

216

217

218

219

220

221

222

223

224

225

226

227

228

229

230

231

232

233

234

235

236

237

238

in 2009, the adhoc expert group in Nanomedicines initiated a series of activities, including the first global conference on the topic, which put together regulators and shareholders from the United States and Japan. During the same period, the European Union dispute on nanomaterials classification related to the "similarity" topic spurred the formation of a TI Pharma (Top Institute Pharma)-based international expert group in the Netherlands (NBCDs expert group) comprising of a variety of experts from academia and industry (Kolosnjaj et al., 2007). The FDA, PDMA/MHL, Canada, Switzerland, Australia, and others all initiated their programs, some of which were coordinated with the EMA. The EMA issued a series of guidance documents on nanostructured materials (Reflection Paper for Generic Nanoparticle on Non-Clinical Studies Iron Medicinal Product Applications e Ema/Chmp/Swp/100094/2011), liposomal comparable models (Reflection Paper for Intravenous Liposomal Products Developed with Liposomes Ema/Chmp/Swp/100094/2011 on the Data Requirements). Recently, a list of the concepts guiding such documents was published (Reflection Paper on data requirements, 2015).

\section{Standards and Guidelines for Nanomedicines as per TGA}

There are several nanomedicines on the market. Still, there is no standard methodology for studying the safety and effectiveness of these nanomedicines, so their development is impeded. The API for nanomedicines, from a regulatory standpoint, requires that the specifications be evaluated within the regulatory framework. The regulatory requirements must be followed by the functional entities present in nanomedicine. The regulatory criteria for medicinal plants and chemical entities have been established (Tambe et al., 2019). The new pharmaceutical development rules described in ICH recommendations Q8, Q9, and Q10 aid in the monitoring and management of key process parameters. The different regulatory authorities engaged in the regulation of nanomedicines include the USFDA, TGA, and EMA (Fan et al., 2012)

\section{TGA}

TGA refers to a broad variety of techniques used in the fabrication and design of methods and processes by regulating size and form at the nanoscale. The TGA regulates goods more effectively since it has a high degree of competence in evaluating new technology. Furthermore, it has the legal power to request extra evidence in support of the safety evaluation of novel materials, and it generally works with applicants who have the technical competence to properly address major safety concerns (Funce, 2007). TGA offers development programs in which the physicochemical characteristics of nanomedicines are compared to those of traditional medications. The therapeutic advantages of the produced nanomedicines can also be assessed. It involves investigating the kinetics of nanoparticles as well as the in-vitro activity of nanoparticles. The toxicity of nanoparticles in vivo and in vitro is next evaluated, followed by risk management and risk reduction. As a result, the TGA itself is on the frontline of regulating nanomedicines (Funce, 2009a). Wherever feasible, the Therapeutic Goods Administration (TGA) aligns the therapeutic drug legislative mechanisms with those of similar international regulatory counterparts. Technical data standards are loosely matched with those outlined in applicable EU and ICH guidance. As EU and ICH technological recommendations are incorporated into Australian law, they provide sponsors with instructions to help them fulfill regulatory criteria (Collins \& Varmus, 2015). The

Peer] reviewing PDF | (2021:06:61967:2:0:NEW 27 Sep 2021) 
239 legislative mechanisms in Australia are largely well adapted to the role of overseeing technology.

240 Nanotechnology-based materials are subject to all regulatory mechanisms. There was no urgent

241 need for significant improvements to the regulatory regimes, although small modifications were

242 needed. The TGA is well-positioned to oversee goods containing nanomedicines because it

243 primarily works in data-rich ecosystems and has a strong degree of experience to put to bear on

244 the evaluation of emerging technology. TGA has the legal right to request supplementary evidence

245 in favor of current content protection assessments (Muthu \& Feng, 2009).

246 Patented Nanoformulation

247 In order to enhance the commercial utility of nanomedicines, several inventors have patented their 248 nanoformulations. Table 2 presents some of the patents based on nanoformulations.

\section{Clinical Trials on Nanomedicine}

250

251

252

253

254

255

256

257

258

259

260

261

262

263

264

265

266

267

268

269

270

271

272

273

274

275

276

277

278

Until 2015, the USFDA licensed 13 nanomedicines to treat various types of pathology. Recently, there has been a surge in the commercialization of these products, as well as a large rise in clinical trials. According to existing statistics, there are 104 ongoing clinical trials, with 82 (78.8 percent) in oncology and 94.8 percent in step I, II, or I - II. 14.6 percent in the EU, 12.2 percent in China, and 4.9 percent in other countries (Albercht et al., 2018). James G. et al. studied BXQ- 350, a nanomedicine agent, in advanced solid tumours, including malignant brain tumours. As BXQ-350 interacts with Saponin C, a naturally expressed protein in humans, it produces DOPS (are fat molecules of Nanobubbles). This formulation has the potential to selectively target and destroy cancerous tumour cells. The results of Phase 1 clinical trial reveal that the patient tolerates the agent well, that there is no dose limiting toxicity, and that there are no significant adverse reactions in the treatment. This study would have 40 new patients from around the country as part of an extended step IB trial (Alvarez et al., 2018).

Clinical trials of anti-cancer nanomedicine were classified into four categories: liposomes, polymeric conjugates, polymeric nanoparticles, micelles, and so on. Approved nanomedicine for cancer has been developed to use the EPR impact principle, with a group of nanomedicines achieving improvements in nanomedicine behaviour by ligand-controlled targeting. EPR-based drugs aim to increase effectiveness and tolerability by modifying medication pharmacokinetics and biodistribution (Hare et al., 2017). According to Roy V. et al., clinical translation for cancer nanomedicine is limited due to a variety of factors such as a lack of understanding of biological barriers in the body, misunderstanding of concepts used in drug delivery, cost-effectiveness, scale up and manufacturing process, and regulatory issues. The analysis of pre-clinical studies over the last ten years shows that only 0.7 percent of the dose has been delivered to tumours (Meel et al., 2017).

Bobo et al. discovered that since the mid-1990s, a total of 13 nanomedicines have been licensed for novel therapeutic indications per five years. This involves the approval of experimental materials as well as their use for additional therapeutic indications (for example, Abraxane ${ }^{\circledR}$ has been accepted for a variety of indications) (Bobo et al., 2016). Four nanomedicines are produced by Katoka that are being run for clinical trials by Chiba, Japan-based nanomedicine manufacturer, Nano Carrier and Nippon Kayaku, a Tokyo-based global chemical and drug firm.

Peer) reviewing PDF | (2021:06:61967:2:0:NEW 27 Sep 2021) 
279 One of the above drugs is in phase 3 of clinical trials for pancreatic cancer, and the drug release is 280 caused by the acidic condition of the tumour (Bourzac, 2016). The mice of various sizes were used, 281 and a dosage of various shaped calcium phosphate nanoparticles was administered. Pancreatic 282 tumours and their vasculature were imaged every 10 minutes for the next 10 hours. The substance 283 was not inserted into these nanoparticles, but they can be used in live animal microscopy. The 284 Koley et al. discovered the particles which are as small as 30 nanometers which leak into 285 pancreatic tumours, but larger particles occur in blood at random due to nanoeruptions (Koley et 286 al., 2019).

287 Doxil and Abraxane are first-generation nanoparticle therapeutics that have already gained 288 acceptance in the clinical cancer research world. Nanoparticle-based therapeutics can sustain their 289

290

291

292

293

294

295

296

297

298

299

300

301

302

303

304

305

306

307

308

309

310

311

312

313

314

315

316

317

318 potential of showing increased medication concentration in tumours with fewer side effects. Most of the nanomedicine is focused on passive targeting that takes advantage of the EPR effect; thus, active targeting technology is being created (Wang et al., 2013). Polymer drug conjugates, micelles, protein-based carriers, liposomes, polymeric nanoparticles, and inorganic nanoparticles are the most common types of nanoparticles accepted in the final stage of clinical trials.

Within the tumour microenvironment, nanoparticles can be engineered to deliver medications sequentially and at specified molar ratios, allowing for maximum synergy that is not achievable with traditional drug delivery methods. For instance, Vyxeos, a liposomal formulation used in the treatment of acute myeloid leukaemia (AML), daunorubicin and codelivers cytarabine in a set molar ratio of 5:1. When compared with a standard daunorubicin and cytarabine regimen, Vyxeos showed enhanced efficacy in two phase 2 clinical trials. Vyxeos was authorised by the FDA in August 2017 for the treatment of AML based on results from five clinical trials, including a pivotal phase 3 trial that met its primary endpoint (Ventola, 2017).

The journey from original discovery to the marketplace for a novel therapy takes about ten years in a clinical trial. Clinical trials take an average of six to seven years to complete. Phase 1 and 2 takes approx. 1 year to 2 years to complete while Phase 3 lasts from 1 to 4 years. Following Phase 3, a pharmaceutical company may submit a New Drug Application (NDA) or a biologics licence application (BLA) to the Food and Drug Administration for approval of the treatment (FDA). The FDA next evaluates the results of all stages of the study to determine whether the drug will be approved and the pharmaceutical company will be able to begin marketing it to the general public. "Post-Approval Research and Monitoring" is a term used to describe Phase 4. Long-term negative effects may take time to manifest, making this a crucial stage (https://www.antidote.me/blog/howlong-do-clinical-trial-phases-take)

\section{Nanomedicines as Drug Therapy}

\section{Cancer}

Over conventional medication construction and distribution, nanotechnology can transform pharmacokinetics and distribution, enhancing potency and reducing side effects. Drug portability, agility, and detainment, as well as selective containment in tumour tissue, are improving, and vectors with potentially successful distribution are being created, aided by the size and surface properties of nanoparticles (Bhandare \& Narayana, 2014). 


\section{Passive targeting}

Because of their small size and surface properties, nanoparticles can pass through blood vessel walls and into tissues. Since tumours have leaky blood vessels and poor lymphatic drainage, nanoparticles may accumulate in them (Sebastian, 2017). EPR is the name given to this passive targeting impact. The EPR improves medication distribution in solid malignant diseases such as breast cancer ( $\mathrm{Wu}$ et al., 2017). However, passive targeting cannot eradicate the possibility of nanocarriers accumulating in tissues with perforated blood vessels, such as the liver or spleen (Trans et al., 2017).

\section{Active targeting}

Active targeting is focused on the targeted targeting of nanoparticles and the molecules expressed on the surfaces of cancerous cells. The theory is used in this targeting to distribute medicines by causing the cell to ingest the nano-carrier into the cancerous cell (Sebastian, 2017). When active targeting is paired with passive targeting, the association of carried drugs with healthy tissue is reduced much more. Via nanotechnology, low drug doses will contribute to greater tumour reduction and increased chemotherapeutic efficacy. Targeting moieties, such as monoclonal antibodies or receptor ligands, are bound to nanocarriers with high affinities for these targets, allowing the nanocarriers to associate and accumulate there (Soares et al., 2018). Conjugation of these ligands has the potential to reduce non-specific uptake of nanocarriers to tissue other than tumour tissue ( $W u$ et al., 2017).

\section{Malaria}

The nanomedicine used for targeting contaminated RBCs and hepatocytes occasionally achieves antimalarial agent targeting. There are two approaches: proactive and aggressive targeting. Passive targeting involves the alteration of the surface with hydrophilic polymers, while active targeting involves the attachment of various ligands to the nano-platforms (Garg et al., 2017).

\section{Passive targeting}

The primary goal of targeting is to increase a drug's plasma maximal concentration (Cmax), which is proportional to its toxicity, and effectiveness is proportional to the region under the curve (AUC) of drug plasma concentration. A higher drug concentration increases drug contact with compromised RBCs and parasite membranes (Gogoi, 2017).

\section{Passive Targeting Using Traditional Nano-Platform-Based DDS}

The intravenous path is used less in malaria care than in leishmaniasis therapy due to the differences in the host cell which is infected. RBCs are neither phagocytically nor endocytically involved. It should be remembered, however, that the nanocarriers that are parentally administered are quickly picked up and transports the drug inside the macrophages by the MPS cells (Pam et al., 2017).

\section{DDS With a Hydrophilic Surface-Modified Nano-Platform Based on Passive Targeting}

The surface alteration of nanoplatforms can be performed by using hydrophilic polymers such as PEG (Poly-Ethylene Glycol), PAA (Poly-Acryl Amide), PVA (Poly-Vinyl Alcohol), PVP (PolyVinyl Pyrrolidine) and Polyxamer. It delays phagocytosis, increases the half-life of the medication in the serum, and allows for the regulation of the drug's biodistribution and pharmacokinetic 
359

360

361

362

363

364

365

366

367

368

369

370

371

372

373

374

375

376

377

378

379

380

381

382

383

384

385

386

387

388

389

390

391

392

393

394

395

396

397

profile. As a result of the hydrophilicity of the polymer, the polymer occupies the surface of the nanoplatforms and thereby preventing the blood plasma opsonins from accessing and attaching to the surface of nano carriers (Muller \& Wallis, 1993).

\section{Active targeting}

Active targeting of drugs associated with nanocarriers is accomplished by conjugating a cellspecific ligand at the carrier's surface, causing the medication to accumulate preferentially in the target cell or tissue (Pam et al., 2017).

\section{Hepatocyte targeting}

The liver is suitable for nanoparticle absorption and targeting due to the open and relatively elevated perforations of the endothelial coating of sinusoids, which lead to the extravasation of larger particles (Gogoi, 2017).

\section{Erythrocyte targeting}

In vitro, nanoplatforms functionalized antibodies demonstrated full intolerance for $\mathrm{pRBCs}$ as opposed to non-infected erythrocytes. Glycosaminoglycans (GAGs) are negatively charged membrane molecules that attach to pRBCs (Wu et al., 2017).

\section{Targeting to Brain}

The parasite $P$. falciparum migrates to the brain in cases of cerebral malaria (CM). The nanoparticles improve drug permeability through a variety of pathways, including transcytosis or endocytosis, inhibition of the transmembrane efflux system (P-glycoprotein), opening tight junctions between endothelial cells, fluidization of the membrane, and toxic effects on the barrier, allowing for restricted permeabilization of brain endothelial cells (Desai et al., 1996). Endothelial cell endocytosis of nanoparticles was improved after drug administration into the brain. Strong lipid nanoparticles (SLNs) of the antimalarial medication quinine were prepared and conjugated with transferrin receptors for active brain targeting (Gogoi, 2017). The parasite P. falciparum migrates to the brain in cases of cerebral malaria $(\mathrm{CM})$. The nanoparticles improve drug permeability through various mechanisms such as transcytosis or endocytosis, inhibition of the transmembrane efflux system (P-glycoprotein), opening tight junctions between endothelial cells, fluidization of the membrane, and toxic effects on the barrier, allowing for restricted permeabilization of brain endothelial cells. Endothelial cell endocytosis of nanoparticles was improved after drug administration into the brain. Strong lipid nanoparticles (SLNs) of the antimalarial medication quinine were prepared and conjugated with transferrin receptors for active brain targeting (Garg et al., 2017).

\section{HIV}

Drug delivery to the brain has been signifying based on the surface receptors but the volume of distribution was limited. Magnetic medication nanocarriers are magnetically applied to the brain for the treatment of HIV/AIDS, which is a non-invasive process (Pam et al., 2017). Under the influence of a static magnetic field, magnetic nanoparticles loaded with 3-Azido-2,3dideoxythymidine-5-triphosphate (AZTTP) successfully cross the BBB, and the virus is released by systemic drug release, accompanied by a virus killing to suppress virus levels. Chiappetta et al. 
398 (2010) created efavirenz-loaded polymeric nanoparticles for the treatment of HIV in infants. This

399

400

401

402

403

404

405

406

407

408

409

410

411

412

413

414

415

416

417

418

419

420

421

422

423

424

425

426

427

428

429

430

431

432

433

434

435

436

437 pharmacotherapy improves the bioavailability of efavirenz $(20 \mathrm{mg} / \mathrm{ml})$.

Various nanomedicine methods for antiretroviral medication oral distribution are being investigated and tested. The current solution is solid medication nanoparticle formulations, which are used to improve the bioavailability of poorly water-soluble products. Macrophages are also a major focus for HIV. Nanocarrier devices that exploit the mannose receptor have been suggested for HIV therapy (Kaushik et al., 2018).

The application of nanotechnology to antiretroviral drug delivery holds promise for HIV cure because it has the potential to change tissue dissemination by targeting drugs to HIV reservoirs and increasing drug half-lives (Curley et al., 2018).

Targeted transmission to HIV reservoir sites will be extremely beneficial since many antiretroviral drugs do not reach these sites optimally, contributing not just to viral survival but also drug resistance growth (Kumar et al., 2015).

\section{Tuberculosis}

The rich layer of mycolic acid in M. tuberculosis cell wall makes the distribution of antitubercular drugs (ATDs) difficult. Since antitubercular medications are hydrophilic in nature, they can cause adverse effects when used for an extended period of time. There are prerequisites for a carrier device that can increase antitubercular medication permeability (Kaushik et al, 2018). This would results in lower levels of the medication being effective and fewer side effects. The creation of novel nanomaterial-based methods for the bioavailability and avoiding drug resistance development for enhancing site-specific targeting of antitubercular drugs.

When compared to its free medication, gentamycin encapsulation into liposomes decreased myocardial infection. The antitubercular drugs' antimycobacterial efficacy was improved after encapsulation in liposomes (Lenjisa et al., 2014).

Nanoparticles are more easily absorbed by cells than larger molecules, making them a promising transport and distribution mechanism. Because of the durability and continuous release of medications from nanoparticles, oral administration is feasible (Kumar et al., 2017).

The use of various nanotechnology-based drug delivery systems, such as polymeric nanoparticles, strong lipid nanoparticles, liquid crystal systems, liposomes, microemulsions, nano micelles, and metal-based nanoparticles (gold nanoparticles, silver nanoparticles, iron oxide nanoparticles)

(Nasiruddin et al., 2017), are an intriguing technique for improving on the most attractive properties of a formulation. Furthermore, particles reflect a future in which activity is guaranteed and complications correlated with TB care can be resolved.

This may increase bioavailability and, as a result, dosing duration, leading to improved patient compliance and drug effectiveness (Da silva et al., 2016).

\section{Market Value of Nanomedicine}

Nanomedicines have been regarded as an analytical and innovative approach to propose drugs since the early days of nano-based technology, with a strong potential for the advancement of therapies for disorders with a poor prognosis, such as cancer, respiratory disease, viruses, neurodegenerative diseases, and non-curable diseases (Nasiruddin et al., 2017). Although they 
438 have been widely used as drug delivery vehicles for targeting purposes since their invention, 439 several nano-based materials are now being produced as therapeutic agents on their own. Among 440 others are reactive oxygen species (ROS) promoters (Costa et al., 2016), hyperthermia agents 441 (Sims et al., 2017), and X-ray enhancers (Thiesen \& Jordan, 2008). Consequently, a growing 442 number of large and small pharmaceutical firms are investigating the potential applications of 443 Nanomedicine (Pottier et al., 2015; Leem, 2017; Ventola CL, 2012). On the other side, as 444 compared to the immense and fascinating research activities in both academia and clinics (Gaspar 445 \& Ducan 2009; Wang et al., 2017; Tinkle et al., 2014; Weissig et al., 2014), the selection of 446 marketed nanomedicines (among which the most popular Onivyde ${ }^{\circledR}(2015)$, Abraxane ${ }^{\circledR}(2005)$, 447 Doxil ${ }^{\circledR}(1995)$, AmBisome $\left.{ }^{\circledR}(1990)\right)$ remains inconsistently poor.

448 Global Nanomedicine Market - Forecast, 2017-2023

449 Nanomedicines have a strong ability to modernize the current scenario of disease prevention, care, 450 and diagnostic processes. From 2017 to 2023, the global nanomedicine market (Global 451 Opportunity Analysis and Industry Forecast from 2017 to 2023) is projected to rise (Figure 1) at a 452 compound annual growth rate (CAGR) of 12.6 percent, reaching \$528 billion in 2019 and \$2,611 453 billion in 2023 (Ragelle et al., 2017; https://www.businesswire.com).

454 The global nanomedicine industry is being propelled by new technology for drug distribution, the 455 benefits of nanomedicine in numerous public healthcare applications, an increase in government 456 interest and investment, and the need for secure and cost-effective therapies (Ragelle et al., 2017). 457 However, environmental concerns (risks associated with nanomedicine) and a lengthy approval 458 procedure limit business expansion. Furthermore, the increased out-licensing of nano drugs and 459 the expansion of healthcare facilities in developing economies are projected to provide numerous 460 opportunities for business growth (https://www.businesswire.com).

461 On a global scale, the nanomedicine market is segmented by use, indication, modality, and area. 462 Drug distribution, vaccinations, regenerative medicine, medical testing, implants, among others 463 are application-based segments. Oncological diseases, immunological diseases, respiratory 464 diseases, infectious diseases, psychiatric diseases, urological diseases, ophthalmological diseases, 465 orthopedic disorders, among others are categorized by indication (Pottier et al., 2015). The 466 modality-based section, on the other side, is divided into diagnosis and therapies.

\section{Growing Application of Nanomedicine Noted in Cardiovascular and Neurology Segments}

469 Cardiovascular, neurology, oncology, anti-infective, and anti-inflammatory are the most significant application categories of nanomedicine. Oncology is expected to dominate the overall industry over the prediction timeframe, with a valuation of $\$ 65.5$ billion by 2019 . When opposed to traditional treatments, nanomedicine has shown many advantages in the management of tumors (Ragelle et al., 2017). Furthermore, as opposed to non-targeted drug therapy, targeted drug delivery has many benefits in terms of accuracy by improved permeation and retention (EPR). Overall, there has been a greater emphasis on numerous research programs including the usage of nanomedicine for cancer treatment.

476 However, in recent years, the emphasis on nanomedicines has shifted to their usage in 477 cardiovascular and neurology. It is mostly due to the increased access to medical records and 
478 technical advances. A CAGR of nearly 16.0 percent over the projected era is expected to develop

479 in the cardiovascular segment (Gogoi, 2017).

480 Nanomedicine and Asia Pacific market

481 Though nano-based products will still be in their early stages of development and advancement in 482 Asia Pacific's developing economies, the sector may over the forecast period is expected to expand.

483 The APAC nanomedicine industry, led by India, China, and Indonesia, is projected to be propelled 484 by increased investments in R\&D as well as the introduction of new drugs/agents and therapies. A 485 deep pipeline centered on different therapeutic areas is also expected to drive the development of 486 the Asia Pacific nanomedicine sector (https://www.reportbuyer.com).

\section{Presence of Patented Nanomedicine to Drive Asia Pacific Market}

488 The Asia Pacific region is expected to expand significantly, owing to increased contributions from 489 China, India, and Indonesia. Furthermore, investments in the field of research and development 490 activities shoot up for the launch of new therapies and medicines are expected to intensify this 491 region's growth in the coming years (http://www.sbwire.com).

492 Insights into Industry

493 In 2016, USD 138.8 billion was the estimated market of global nanomedicines. Technological 494 advancements coupled with appropriate applications in early disease diagnosis, preventive 495

496

497

498

499

500

501

502

503

504

505

506

507

508

509

510

511

512

513 intervention, and chronic and acute disease prophylaxis are expected to fuel market growth. Nanotechnology is the nanometric miniaturization of larger products and chemicals, which has significantly revolutionized medication administration and will continue to dominate technical adoption until 2025 (http://www.sbwire.com).

Expected advances in nanorobotics as a result of increased investment from government agencies are expected to bring potential to the industry. Nanorobotics research programs aiming to kill cancer cells without disrupting adjacent tissues are expected to accelerate development until 2025 (Figure 1).

A potential pipeline of goods is expected to propel the industry with potential development avenues focused on nano molecules and related innovations. The involvement of approximately $40 \%$ of medicines in phase II clinical research is likely to result in some key commercialization during the next decade, influencing sales generation over the forecast era. Because of the tailored therapy options for eradicating genetic disorders, this technology is a promising option for precision medicine (Desai et al., 1996).

\section{Insights into Product}

Because of the inclusion of many drugs in this segment, In 2016, therapeutics described a key portion of revenue. Therapeutic drugs and instruments, as well as medication delivery mechanisms, are used to cure a variety of diseases (Costa et al., 2016).

514 unique physicochemical properties. Furthermore, nanotechnology-enabled drug delivery systems

515 have two major advantages:

516 1) Improved cellular penetration.

517 2) Toxicity associated with the drugs is reduced. 
518 These benefits are expected to draw attention to nanotechnology for drug delivery as a product 519 launch, affecting growth throughout the forecast period. Growth in this segment is expected to be 520 driven by the production of novel delivery products using different forms of nanoparticles 521 (https://www.transparencymarketresearch.com).

522 Insights into Application

523 Oncology, respiratory disorders, cardiology, orthopaedics, among other applications are included 524 in the segmentation. In 2016, oncology led with a revenue share of about 47 percent. A significant 525 number of medications in the clinical phases of development for cancer treatment, as well as 526 developments in the implementation of therapeutic and diagnostic particles and devices, are to 527 blame for a larger proportion of cancer diseases (Gogoi, 2017). The tool could be used for both

528

529

530

531

532

533

534

535

536

537

538

539

540

541

542

543

544

545

546

547

548

549

550

551

552

553

554

555

556 active and passive cancer targeting. Cardiology, on the other hand, is projected to develop the most, with a CAGR of around 11.7 percent over the forecast timeline, owing to the availability of opportunities such as demand for novel therapeutic nanovectors, nanostructured stents, and tissue repair inserts (Mousa, 2017).

\section{Nanomolecule Type Insights}

Several forms of nanomolecules can be used in the healthcare industry. Quantum dots, nanoparticles, nanoshells, nanotubes, and nanodevices are examples of these compounds. Metal and metal oxide nanoparticles, liposomes, dendrimers, and conjugated polymers are examples of nanoparticles. The use of nanoparticles in various fields of healthcare is projected to accelerate development in the coming years ( $h t t p: / / w w w . s b w i r e . c o m)$. The ability of these molecules to bind to chemical moieties in the form of scaffolds allows them to conduct a variety of functions. One of the most significant methods of nanotechnology is the use of nanoparticles for active targeting by attaching them to ligands of cell receptors. Because of their extensive use in diagnostics, metal and metal oxide nanoparticles are expected to be in high demand in this sector. It is expected that research to improve theranostics would affect industrial development (Bawa et al., 2008).

\section{Regional Insights}

North America led the nanomedicine industry with a sales share of more than 42 percent (Figure 2) due to the presence of exponentially growing partnerships between established businesses in the field and nanomedicine startup organizations. Furthermore, government support, along with expanded R\&D spending, accounts for the area's largest share of industrial space (Soares et al., 2018). The details of nanoparticles approved by FDA (Table 3) with their use in treatment of different disease. A variety of nanoformulations with pharmaceutical application are commercially available (Table 4).

\section{Public Acceptance of Nanomedicine: A Personal Perspective}

A lack of knowledge of a subject, results in narrow interpretations, including uninformed biases and comparisons. Prior biotechnologies, in the area of nanotechnology, have damaged the general understanding of nanotechnology solely by affiliation. Although societal bias is sluggish to change, it is possible that medical applications of nanotechnology would spark renewed interest 
557 and confidence in the sector by allowing people to live longer lives

558 (https://www.grandviewresearch.com).

559 Challenges and Opportunities in Future Nanomedicine: An Industry 560 Perspective

561 If somehow the scope of nanotechnology technologies in medicine expands, it is critical to 562 consider and advance contributions relevant to public health at the same time. A vast variety of 563 nanomedicine advances have the potential to affect almost any medical specialty and reveal new 564 approaches to increase the quality and length of life - these gains can be evaluated at both the 565 human and community levels (Berube, 2009).

566 The unusual characteristics and phenomena that manifest due to their limited scale make 567 nanotechnology applications appealing. The most commonly used scale for nanotechnology is 1$568100 \mathrm{~nm}$ (Pautler \& Brenner, 2010).

569 Engineering materials of this scale enables new medicinal treatments such as the development of

570 nanoparticle-based medications with increased sensitivity, resulting in fewer adverse effects for 571 patients (http://www.nano.gov).

572 Global research is currently ongoing to establish nanotechnology applications in cardiology, 573 neurology, and a variety of other medical specialties (Bawarski et al., 2008).

574 Nanomedicines have been studied for their potential use in the targeted delivery of drugs to combat

575 a wide range of diseases. This market viewpoint focuses solely on oncology-based nanomedicine 576 therapeutics, which attract roughly two-thirds of study attention (Kostarelos et al., 2009).

577 Etheridge et al. focus on public health interests which is critical to effectively advancing the 578 discipline and evolving medical technology for clinical use. Simultaneously, information deficits 579 about the fate and transport of engineered nanoparticles in biological systems must be resolved 580 continuously (Etheridge et al., 2013).

581 In view of the evidence mentioned above, nanotechnology has significant applications in 582 healthcare management. Several nano-therapeutics have been licensed by the FDA for the 583 treatment of hepatitis, cancer, cardiovascular disease, neurological disease, autoimmune disease, 584 diabetes, elevated cholesterol, Parkinson's disease, and some infectious diseases during the last 585 two decades (Oberdorster et al., 2005).

586 Hundreds of nano carrier-based drugs are still currently in different stages of preclinical and 587 clinical production (http://nano.cancer. gov).

588 The use of nanotechnology in the area of medicine has already resulted in several breakthroughs 589 and is rapidly progressing toward being a critical component of the healthcare system. This is 590 shown by the growing number of scientific publications and patents awarded in the area of 591 nanocarrier systems for drug delivery (Etheridge et al., 2013).

592 The transition of scientific discovery into marketable goods remains a problem, and the future of 593 developing nanotherapeutics is dependent on turning promising research findings into profitable 594 commercial technologies for stakeholders. Nanotechnology has the potential to significantly 595 improve precision medicine soon. Nano-diagnostics should be used more extensively to increase 596 the sensitivity and reliability of diagnostic tests. Newer and more accurate nanoparticles may be 
597 detected, allowing us to make more precise disease diagnoses and management decisions

598 (http://nano.cancer. gov).

\section{Conclusions and Future Perspectives}

600 Novel nanotechnology-enabled systems show a promising approach to improving clinical 601 possibilities and providing many benefits that are absent in existing therapeutic methods. In this

602 review, we discussed an effort to highlight previous studies, patents, clinical investigations in the 603 last ten years, industrial utilities, and to attract medical attention to the potential prospects of 604 nanomedicines for their promising therapeutic efficacies. Nanomedicine Market Value, Global 605 Nanomedicine Market Forecast, 2017-2023, Growing Use of Nanomedicine in Cardiovascular and 606 Neurology Segments, The presence of patented nanomedicine would drive the Asia Pacific 607 demand for nanomedicine. Analysis of the Nanomedicine Market by Product (Therapeutics, 608 Regenerative Medicine, Diagnostics), Application (Clinical Oncology, Infectious Diseases), 609 Nanomolecule (Gold, Silver, Iron Oxide, Alumina), and Segment Forecasts, 2018 - 2025, A 610 personal viewpoint on public acceptance of nanomedicine. Future nanomedicine's challenges and 611 opportunities: A detailed business perspective has been explored. The use of nanomedicines as a 612 medication therapy in the treatment of global diseases such as cancer, malaria, HIV, and 613 tuberculosis has been highlighted. Further studies in this new field can be guided by 614 multidisciplinary techniques along with industry-academia collaboration. Until now, translating 615 experimental progress into marketable nano-products has been difficult, and the success of new 616 nanomedicines is dependent on turning promising research results into profitable industrial 617 technologies for stakeholders. Nanotechnology-based nano-systems can contribute to significant 618 advances in personalized medicine in the immediate future. Nano-diagnostics should be used more 619 extensively to increase the sensitivity and reliability of diagnostic tests. Newer and more accurate 620 nanomedicines may be detected, leading to more precise cancer detection and treatment. Finally, 621 the advancements and unusual characteristics outlined herein can pave the way for modern, highly 622 efficient, and essential nanosystems.

623

624 Acknowledgements

625 All the authors of this manuscript are thankful to their respective Departments/Universities for 626 successful completion of this study.

627

628 Funding

629 Authors have not received any funding for the work.

630

631 Grant disclosures

632 Not Applicable

633

634 Competing Interests

635 The authors declare there are no competing interests. 636 


\section{Author Contributions}

638 All the authors of this manuscript contributed equally to this study.

639

640

Abbreviations

641

642 TGA - Therapeutic Goods Administration

643 API - Active Pharmaceutical Ingredient

644 NCEs - New Chemical Entities

645 QbD - Quality by design

646 PAT- Process Analytical Technology

647 ICH- International Conference on Harmonization

648 USFDA - United State Food \& Drug Administration

649 EMA- European Medicines Agency

650 MAA - Marketing Authorization Application

651 FDA - Food \& Drug Administration

652 PDMA - Pharmaceutical and Medical Device Agency

653 MHLW - Ministry of Health, Labor and Welfare

654 QALEYs - Quality Adjusted Life Expectancy Years

655 HTA - Health Technology Assessment

656 NBCDs - Non-Biological Complex Drugs

657 ITF - Innovation Task Force

658 TI Pharma - Top Institute Pharma

659 AML - Acute Myeloid Leukaemia

660 NDA - New Drug Application

661 BLA - Biologics Licence Application

662 RBCs - Red Blood Cells

$663 \mathbf{C}_{\mathbf{m a x}}-$ Concentration Maximum

664 R\&D - Research \& Development

665 ROS - Reactive Oxygen Species

666 AZTTP - 3 Azido-2,3-dideoxythymidine-5-triphosphate

667 BBB - Blood Brain Barrier

668

669

\section{References}

670

671 Albercht B, Andersen S, Chauhan K, Graybosch D, Menu P. 2018. Persuing breakthrough in 672 cancer drug development. McKinsey Cancer Center. 1-9.

673 Allen TM, Cullis PR. 2013. Liposomal drug delivery systems: from concept to clinical 674 applications. Advance Drug Delivery Reviews 65(1):36-48. DOI 10.1016/j.addr.2012.09.037

675 Alvarez P, Aranega A, Molina JA. 2018. Nanotechnology and Nanomedicine: Keys to the 676 Development of Clinical Trials and Obtaining of New Drugs. International Journal of Scientific 677 Research 7(4):34- 36.

678 Anselmo AC, Mitragotri S. 2019. Nanoparticles in the clinic: An update. Bioengineering \& 679 translational medicine 4(3):10143. DOI 10.1002/btm2.10143 
680 Bawa R, Melethil S, Simmons WJ, Harris D. 2008. Nanopharmaceuticals: patenting issues and

681

682

683

684

685

686

687

688

689

690

691

692

693

694

695

696

697

698

699

700

701

702

703

704

705

706

707

708

709

710

711

712

713

714

715

716

717

718

FDA regulatory challenges. The SciTech Lawyer 5(2):1-6.

Bawarski WE, Chidlowsky E, Bharali DJ, Mousa SA. 2008. Emerging nanopharmaceuticals. Nanomedicines 4:273-282. DOI 10.1016/j.nano.2008.06.002

Berube DM. 2009. The public acceptance of nanomedicine: a personal perspective. Wiley Interdisciplinary Rev. Nanomedicine and Nanobiotechnology 1(1):2-5. DOI 10.1002/wnan.30

Bhandare N, Narayana A. 2014. Applications of nanotechnology in cancer: A literature review of imaging and treatment. Journal of Nuclear Medicine and Radiation Therapy 5(4):1-9. DOI 10.4172/2155-9619.1000195

Bharali DJ, Siddiqui IA, Adhami VM, Chamcheu JC, Aldahmash AM, Mukhtar H, Mousa SA. 2011. Nanoparticle delivery of natural products in the prevention and treatment of cancers: current status and future prospects. Cancers 3(4):4024-4045. DOI 10.3390/cancers3044024

Bobo D, Robinson KJ, Islam J, Thurecht KJ, Corrie SR. 2016. Nanoparticle-based medicines: A Review of FDA approved materials and Clinical Trials to date. Pharmaceutical research. 33(10):2373-87. DOI 10.1007/s11095-016-1958-5

Bourzac K. 2016. News Feature: Cancer Nanomedicine, reengineered. Proceedings of the National Academy of Science 113(45):12600-12603. DOI 10.1073/pnas. 1616895113

Caminade AM, Majoral JP. 2010. Dendrimers and nanotubes: a fruitful association. Chemical Society Reviews 39:2034-2047

Canto AB, Rasilla CGDL, Casadamon LI, Garreta JMI, Arbella NM, Moro JM. 2018. Core shell zein nanoparticles for the encapsulation of compounds, process for their preparation and uses thereof (European Patent No. EP3581176A1). European Patent Office.

Chiara DF, Leonardo N, Nicolo' Pettenuzzo B. 2016. Composti di coordinazione, sintesi, nanoformulazione ed uso degli stessi in oncologia (IT201600122363A1).

Chithrani BD, Ghazani AA, Chan WW. 2006. Determining the size and shape dependence of gold nanoparticle uptake into mammalian cells. Nano Letters 6:662-668. DOI 10.1021/n1052396o Collins FS, Varmus H. 2015. A new initiative on precision medicine. The New England Journal of Medicine 372:793-795. DOI 10.1056/NEJMp1500523

Costa A, Pinheiro M, Magalhães J, Ribeiro R, Seabra V, Reis S, Sarmento B. 2016. The formulation of nanomedicines for treating tuberculosis. Advanced Drug Delivery Reviews 102:102-115. DOI 10.1016/j.addr.2016.04.012

Curley P, Liptrott NJ, Owen A. 2018. Advances in nanomedicine drug delivery applications for HIV therapy. Future Sci OA 4(1):1-6. DOI 10.4155/fsoa-2017-0069

Da Silva PB, de Freitas ES, Bernegossi J, Goncalez ML, Sato MR, Leite C, Pavan F, Chorilli M. 2016. Nanotechnology-based drug delivery systems for treatment of tuberculosis - A review. Journal of Biomedical Nanotechnology.12(2):241-260. DOI 10.1166/jbn.2016.2149

Davis PJ, Davis FB, Mousa SA. 2010. Nanoparticle and polymer formulation for thyroid hormone, analogus, antagonists and formulations and uses thereof (European. Patent No. EP 2442 800 B1). European Patent office.

Peer] reviewing PDF | (2021:06:61967:2:0:NEW 27 Sep 2021) 
719 Desai MP, Labhasetwar V, Amidon GL, Levy RJ. 1996. Gastrointestinal uptake of 720 biodegradable microparticles: Effect of particle size. Pharmaceutical Research 13(12):1838-1845. 721 DOI 10.1023/a:1016085108889

722 Desai N, Trieu V, Yao Z, Louie L, Ci S, Yang A, Tao C, De T, Beals B, Dykes D, Noker P. 723 2006. Increased antitumor activity, intratumor paclitaxel concentrations, and endothelial cell 724 transport of cremophor-free, albumin-bound paclitaxel, ABI-007, compared with cremophor725 based paclitaxel. Clinical cancer research 12(4):1317-1324. DOI 10.1158/1078-0432

726 Desai NP, Tao C, De T, CI XS, Trieu V. 2009. Nanoparticles formulations and uses thereof (U.S. 727 Patent No. 2009/0263483 Al). U.S. Patent trademark office.

728 Devraj R, Chhatoi P, Pravathabhatla NHK, Deshmukh AV, Chintabhatla KK. 2015. 729 Composition and method of producing nanoformulation of water insoluble bioactives in aqueous 730 base. (International Patent No. WO 2015/155703 A3). World intellectual property organization.

731 Dobrovolskaia MA, McNeil SE. 2007. Immunological properties of engineered nanomaterials. 732 Nature Nanotechnology 2(8):469-478. DOI 10.1038/nnano.2007.223

733 Dorbeck-Jung BR, Chowdhury N. 2011. Is the European medical products authorisation 734 regulation equipped to cope with the challenges of nanomedicines? Law Policy 33:276-303. DOI 735 10.1111/j.1467-9930.2011.00339.x

736 Duncan R, Izzo L. 2005. Dendrimer biocompatibility and toxicity. Advances in Drug Delivery 737 Reviews 57:2215-2237. DOI 10.1016/j.addr.2005.09.019

738 Ehmann F, Sakai-Kato K, Duncan R, Ossa DH, Vidal JM, Kohli A, Tothfalusi L, Sanh A, 739 Tinton S, Robert JL, Lima BS, Amati MP. 2013. Next-generation nanomedicines and 740 nanosimilars: EU regulators' initiatives relating to the development and evaluation of 741 nanomedicines. Nanomedicines 8(5):849-56. DOI 10.2217/nnm.13.68

742 Etheridge ML, Campbell SA, Erdman AG, Haynes CL, Wolf SM, McCullough J. 2013. The

743 big picture on nanomedicine: the state of investigational and approved nanomedicine products.

744 Nanomedicine 9(1):1-14. DOI 10.1016/j.nano.2012.05.013

745 Fan Z, Senapati D, Singh AK, Ray PC. 2012. Theranostic magnetic core-plasmonic shell star 746 shape nanoparticle for the isolation of targeted rare tumor cells from whole blood, fluorescence 747 imaging, and photothermal destruction of cancer. Molecular Pharmacology 10(3):857-866. DOI $74810.1021 / \mathrm{mp} 300468 \mathrm{q}$

749 Farokhzad OC, Kolishetti N, Dhar S, Lippard SJ, Langer RS, Valencia PM. 2013. Particles 750 for multiple agent delivery (U.S. Patent No US 2013/0017265 Al). U.S. Patent and trademark 751 office.

752 Faunce TA 2007. Nanotherapeutics: new challenges for safety and cost-effectiveness regulation

753 in Australia. Medicinal Journal of Australia 186(4):189-191. DOI: 10.5694/j.1326754 5377.2007.tb00860.x

755 Faunce TA 2009a. Policy challenges of naomedicine for Australia's PBS. Australian Health 756 Review 33(2):258-267. 
757 Garg A, Bhalala K, Tomar DS, Wahajuddin M. 2017. Nanomedicine: Emerging Trends in 758 Treatment of Malaria. Antimicrobial Nanoarchitectonics. 475-509. DOI 10.1016/B978-0-323759 52733-0.00017-3

760 Gaspar R, Ducan R. 2009. Polymeric carriers: preclinical safety and the regulatory implications 761 for design and development of polymer therapeutics. Advances in Drug Delivery 61:1220-1231. 762 DOI 10.1016/j.addr.2009.06.003

763 Gaspar R, Florindo H, Silva L, Videira MA, Corvo ML, Martins BF, Lima BS. 2014. 764 Regulatory aspects of oncologicals: nanosystems main challenges. Nano Oncology 425-452. DOI 765 10.1007/978-3-319-08084-0_15

766 Gaspar RS. 2010. Therapeutic products: regulating drugs and medical devices. International 767 Handbook on Regulating Nanotechnologies, Edward Elgar Publishing Limited, Northampton, 768 MA, USA 291-320. DOI http://www.imed.ul.pt

769 Gaynes R. 2017. The discovery of Penicillin-New insights after more than 75 years of clinical 770 use. Emerging Infectious Diseases 23(5):849-853. DOI http://dx.doi.org/10.3201/eid2305.161556

771 Gogoi M. 2017. Recent Advances in Nanomedicine for Antimalarial Drug Delivery. Journal of 772 Biology and Medicinal research 4(2):151-161.

773 Guo JW, Lee YH, Huang HW, Tzou MC, Wang YJ, Tsai JC. 2014. Development of Taiwan's 774 strategies for regulating nanotechnology-based pharmaceuticals harmonized with international 775 considerations. Internatational Journal of nanomedicines 9:4773-4783. DOI 10.2147/ijn.s68134

776 Halvor N, Eyolf L. 2010. Antimicrobial composition from copepods (European Patent No. EP 2 777346516 B1). European Patent Office.

778 Hare JI, Lammers T, Ashford MB, Puri S, Storm G, Barry ST. 2017. Challenges and strategies 779 in anti-cancer nanomedicine development: An industry perspective. Advances in drug delivery 780 reviews 108:25-38. DOI 10.1016/j.addr.2016.04.025

781 http://www.sbwire.com/press-releases/nanomedicine-market-worth-177-billion-by-2019-cagr.

782 https:/www.businesswire.com/news/home/20160404006116/en/Global-Nanomedicine-Market-

783 Worth-USD-528-Billion.

784 https://www.grandviewresearch.com/industry-analysis/nanomedicine-market.

785 https://www.reportbuyer.com/product/5139404.

786 https:/www.transparencymarketresearch.com/pressrelease/nanomedicine-market.htm.

787 Hurby M, Brezaniova I, Kral V. 2019. Photoactivable nanoparticles for photodynamic 788 applications, its method, preparation, the pharmaceutical composition her containing and their use 789 (Patent No. 307 681).

790 https://www.antidote.me/blog/how-long-do-clinical-trial-phases-take

791 Jiang H, Xing L, Yang C. 2019. Amphiphilic anti-inflammatory platinum nanoparticles and 792 preparation methods therefor (U.S. Patent No. US 2019/0358345 Al). U.S. Patent and trademark 793 office.

794 Kalepu S, Nekkanti V. 2015. Insoluble drug delivery strategies: review of recent advances and 795 business prospects. Acta Pharmaceutica Sinica B 5(5):442-453. DOI 10.1016/j.apsb.2015.07.003 
796 Kaushik A, Jayant RD, Nair M. 2018. Nanomedicine for neuro HIV/AIDS management. 797 Nanomedicines 13(7):669-673. DOI 10.2217/nnm-2018-0005

798 Knox L, Dunning M, Davies CA, Bennet RM, Sion TW, Phipps K, Stevenson V, Hurlin C, 799 Lewis K. 2019. Safety, feasibility, and effectiveness of virtual pulmonary rehabilitation in the real 800 world. International Journal of Chronic Obstructive Pulmonary Disease 14:775-780. DOI 801 10.2147/COPD.S193827

802 Koley H, Mukherjee P, Nag D, Sinha R, Chakrabarti K. 2019. Alginate chitosan 803 nanoformulation of OMPA-A shigella protein subunit (U.S. Patent No. US 2019/0060436 Al) U.S. 804 Patent trademark office.

805 Kolosnjaj J, Szwarc H, Moussa F. 2007. Toxicity studies of fullerens and derivatives. Advances 806 in Experimental Medical Biology 620:168-80. DOI 10.1007/978-0-387-76713-0_13.

807 Kostarelos K, Bianco A, Prato M. 2009. Promises, facts and challenges for carbon nanotubes in 808 imaging and therapeutics. Nature Nanotechnology 4(10):627-633. DOI 10.1038/nnano.2009.241

809 Kumar L, Verma S, Prasad DN, Bhardwaj A, Vaidya B, Jain AK. 2015. Nanotechnology: A 810 magic bullet for HIV AIDS treatment. Artificial Cells, Nanomedicine and Biotechnology 811 43(2):71-86. DOI 10.3109/21691401.2014.883400

812 Kumar N, Das B, Patra S. 2017. Drug Resistance in Tuberculosis: Nanomedicines at Rescue.

813 Antimicrobial Nanoarchitectonics. 261-278. DOI 10.1016/B978-0-323-52733-0.00010-0

814 Leem C. 2013. Biotech, Applications Des Nanotechnologies à la Médecine. (Consulted on August 815 2017).

816 Lenjisa JL, Woldu MA, Satessa GD. 2014. New hope for eradication of HIV from the body: the 817 role of polymeric nanomedicines in HIV/AIDS pharmacotherapy. Journal of Nanobiotechnolology 818 12(1):1-6. DOI 10.1186/1477-3155-12-9

819 Lillard JW, Singh R, Singh S. 2015. Nanoparticles for delivery of active agents (U.S. Patent No. 820 US 8,962,030 B2). U.S. Patent trademark office.

821 Lohcharoenkal W, Wang L, Chen YC, Rojanasakul Y. 2014. Protein nanoparticles as drug 822 delivery carriers for cancer therapy. BioMed Research International:1-12. DOI $823 \quad 10.1155 / 2014 / 180549$

824 Maximilien J, Beyazit S, Rossi C, Haupt K, Bui BTS. 2015. Nanoparticles in biomedical 825 applications. Measuring Biological Impacts of Nanomaterials:177-210. DOI 826 10.1007/11663_2015_12

827 Meel VD, Roy, Lammers T, Hennink WE. 2017. Cancer nanomedicines: Oversold or 828 underappreciated. Expert Opinion on Drug Delivery 1-5. DOI 10.1080/17425247.2017.1262346

829 Merchant GE, Sylvester DJ, Abbott KW, Danfroth TL. 2009. International harmonization of 830 regulation of nanomedicine. Stud in Ethics, Law, and Technology 3(3):1-16. DOI 10.2202/19418316008.1120

832 Mitchell MJ, Billingsley MM, Haley RM, Wechsler ME, Peppas NA, Langer R. 2021. 833 Engineering precision nanoparticles for drug delivery. 2021. Nature Reviews 20:101-124. DOI 834 10.1038/s41573-020-0090-8. 
835 Mousa SA, Qari MH, Ardawi MS. 2017. Compositions of novel bone patch in bone and vascular 836 regeneration (U.S. Patent No US 9,707,318 B2). U.S. Patent and trademark office.

837 Mousa SA. 2017. Composition and method for sulfated non-anticoagulant low molecular weight 838 heparins in cancer and tumor metastatis (U.S. Patent No. US, 9,572,831 B2). U.S. Patent and 839 trademark office.

840 Mousa SA. 2017. Nano-targeted delivery of protease, polymerase inhibitors with or without 841 immune modulators in the treatment of Hepatitis C (U.S. Patent No US 9,597,351 B2). U.S. Patent 842 and trademark office.

843 Mousa SA. 2018. Nanoformulation and methods of use of thyroid receptor Beta 1 agonists for 844 liver targeting (U.S. Patent No US 9,956,291 B2). U.S. Patent and trademark office.

845 Müller RH, Wallis KH. 1993. Surface modification of i.v. injectable biodegradable nanoparticles 846 with poloxamer polymers and poloxamine 908. International Journalof Pharmaceutics 89(1):25847 31. DOI https://doi.org/10.1016/0378-5173(93)90304-X

848 Muthu MS, Feng SS, 2009. Pharmaceutical stability aspects of nanomedicines. Nanomedicine 849 4(8):857-60. DOI 10.2217/nnm.09.75

850 Nadeem M. 2020. Translational Nanomedicine lab to clinic. Intelligent Nanomaterials for Drug 851 Delivery Applications:141-162. DOI 10.1016/B978-0-12-817830-0.00008-4

852 Nasiruddin M, Neyaz M, Das S. 2017. Nanotechnology-Based approach in tuberculosis 853 treatment. Tuberculosis Research and Treatment. 1-13. DOI 10.1155/2017/4920209

854 National Cancer Institute Alliance for Nanotechnology in Cancer. Learn About Nanotechnology 855 in Cancer. Available from: http://nano.cancer. gov/about $/ \mathrm{mission} /$ faq.asp.

856 National Cancer Institute. A Snapshot of Nanotechnology [updated 2009 Sep]. Available from: 857 http://www.cancer.gov/aboutnci/servingpeople/ snapshots/nanotech.pdf.

858 National Nanotechnology Initiative. What is Nanotechnology? Available from: 859 http://www.nano.gov/html/facts/whatIsNano.html.

860 Navalakhe RM, Nandedkar TD. 2004. Application of nanotechnology in biomedicine. Indian 861 Journal of Experimental Biology 45(2):160-5 PMID 17375555.

862 Obeid MA, Tate RJ, Mullen AB, Ferro VA. 2018. Lipid-based nanoparticles for cancer 863 treatment. Lipid Nanocarriers for Drug Targeting:313-359. DOI 10.1016/B978-0-12-813687864 4.00008-6

865 Oberdorster G, Maynard A, Donaldson K, Castranova V, Fitzpatrick J, Ausman K, Karn B, 866 Kreyling W, Lai D, Olin S, RiviereNM, Warheit D, Yang H, A report from the ILSI research 867 foundation/Risk science institute nanomaterial toxicity screening working group. 2005.

868 Principles for characterizing the potential human health effects from exposure to nanomaterials: 869 elements of a screening strategy. Particle and Fibre Toxicology 2(8):1-35. DOI 10.1186/1743870 8977-2-8

871 Oberdorster G. 2009. Safety assessment for nanotechnology and nanomedicine: concepts of 872 nanotoxicology. Journal of Internal Medicine 267(1):89-105. DOI 10.1111/j.1365873 2796.2009.02187.x 
874 Orza AI. 2017. Novel anti-wrinkle and anti-aging nanoformulations and method of preparation 875 using novel nano co-delivery system (U.S. Patent No. US 2017/0157005 Al). U.S. Patent 876 trademark office.

877 Pam DD, Omalu IC, Innalegwu DA, Opemipo BO, Hassan FS, Kasim JH, Saba MH, Abuchi 878 NA, Adeniyi KA. 2017. An Overview of Application of Nanotechnology in Malaria Control. 879 Online Journal of Health and Allied Sciences 16(2):1-4. DOI http://www.ojhas.org/issue62/2017880 2-10.html.

881 Patra JK, Das G, Fraceto LF, Campos EVR, Torres MDPR, Torrs LSA, Torres LAD, Grillo 882 R, Swamy MK, Sharma S, Habtemariam S, Shin HS. 2018. Nano based drug delivery systems: 883 recent development and future prospects. Journal of Nanobiotechnology 16(1):71. DOI 884 10.1186/s12951-018-0392-8

885 Pautler M, Brenner S. 2010. Nanomedicine: promises and challenges for the future of public 886

887 Pottier A, Borghi E, Levy L. 2015. The future of nanosized radiation enhancers. The British health. Internnational Journal of Nanomedicine 5:803-809. DOI 10.2147/IJN.S13816 888 Journal of Radiology 88:1-3. DOI 10.1259/bjr.20150171

889 Ragelle H, Danhier F, Préat V, Langer R, Anderson DG. 2017. Nanoparticle-based drug 890 delivery systems: a commercial and regulatory outlook as the field matures. Expert Opinion in 891 Drug Delivery 14:851-864. DOI 10.1080/17425247.2016.1244187

892 Raj S, Khurana S, Choudhari R, Kesari KK, Kamal MA, Garg N. 2019. Specific targeting 893 cancer cells with nanoparticles and drug delivery in cancer therapy. Seminars in Cancer Biology 894 1-53. DOI 10.1016/j.semcancer.2019.11.002

895 Reflection paper on the data requirements for intravenous iron-based nano-colloidal products 896 developed with reference to an innovator medicinal product. 2015. European medicines agency. 897 2-11. EMA/CHMP/SWP/100094/2011

898 Sahoo SK, Parveen S, Panda JJ. 2007. The present and future of nanotechnology in human health 899 care. Nanomedicine 3:20-31. DOI 10.1016/j.nano.2006.11.008

900 Sainz V, Conniot J, Matos AI, Peres C, Zupancic E, Moura L, Silva LC, Florindo HF, Gasper 901 RS. 2015. Regulatory aspects on nanomedicines. Biochemical and biophysics research 902 communications 468(3):504-10. DOI 10.1016/j.bbrc.2015.08.023

903 Sebastian R. 2017. Nanomedicine-the Future of Cancer Treatment: A review. Journal of Cancer 904 Prevention and Current Research 8(1):1-6. DOI 10.15406/jcpcr.2017.08.00265

905 Shrivastava S, Dash D. 2009. Applying nanotechnology to human health: revolution in 906 biomedical sciences. Journal of Nano technology 1-14 DOI 10.1155/2009/184702

907 Sims CM, Hanna SK, Heller DA, Horoszko CP, Johnson ME, Bustos A, Reipa V, Riley K, 908 Nelson B. 2017. Redox-active nanomaterials for nanomedicines applications. Nanoscale 9:15226909 15251. DOI 10.1039/c7nr05429g.

910 Soares S, Sousa J, Paris A, Vitorino C. 2018. Nanomedicine: Principles, properties, and 911 regulatory Issues. Frontiers in chem 6(360):1-15. DOI 10.3389/fchem.2018.00360. 
912 Stanczyk FZ, Lee JS, Santen RJ. 2007. Standerdization of steroid hormone assays: why, how, 913 and when?. Canc Epidemiol Biomarkers Prev 16(9):1713-1719. DOI 10.1158/1055-9965.EPI-069140765.

915 Tambe V, Maheshwari R, Chourasiya Y, choudhary H, Gorain B, Tekade R. 2019. Clinical 916 aspects and regulatory requirements for nanomedicines. Basic Fundamentals of Drug Delivery 917 733-752. DOI 10.1016/B978-0-12-817909-3.00018-2

918 Thiesen B, Jordan A. 2008. Clinical applications of magnetic nanoparticles for hyperthermia. 919 International Journal of Hyperthermia. 24:467-474. DOI 10.1080/02656730802104757

920 Tinkle S, McNeil SE, Muhlebach S, Bawa R. 2014. Nanomedicines: addressing the scientific 921 and regulatory gap. Annals of the New York Academy of Science 1313:35-56. DOI $92210.1111 /$ nyas. 12403

923 Toriumi M, Itani T. 2018. Photosensitive composition and pattern formation method (U.S. Patent 924 No. US 10,095,108 B2). U.S. Patent and trademark office.

925 Tran S, DeGiovanni PJ, Piel B, Rai P. 2017. Cancer nanomedicine: a review of recent success 926 in drug delivery. Clinical and Translational Medicine 6(1):1-21. DOI 10.1186/s40169-017-01759270

928 Trie V, D'Cruz O, Desai NP. 2012. Combinations and modes of administration of therapeutic 929 agents and combination therapy (U.S. Patent No. US 2012/0128732 Al). U.S. Patent trademark 930 office.

931 Ventola CL. 2012. The nanomedicine revolution: part 1: emerging concepts. Pharmacy and 932 Therapeutics 37:512-525. PMID:23066345

933 Ventola CL. 2017. Progress in nanomedicine: approved and investigational nanodrugs. Pharmacy 934 and Therapeutics 42(12):742-755.

935 Wang R, Billone PS, Mullett WM. 2013. Nanomedicine in action: An Overview of Cancer 936 Nanomedicine on the market and in Clinical Trials. Journal of Nanomaterials. 1-12. DOI $93710.1155 / 2013 / 629681$

938 Wang X, Wang J, Li Q, Jiang H. 2017. Tumor-targeting multimode imaging method for living 939 body based on gold nanoclusters (U.S. Patent No. US 9,724,431 B2). U.S. Patent and trademark 940 office.

941 Wang YF, Liu L, Xue X, Liang XJ. 2017. Nanoparticle-based drug delivery systems: What can 942 they really do in vivo?. F1000Research 6:1-8. DOI 10.12688/f1000research.9690.1

943 Weissig V, Pettinger T, Murdock N. 2014. Nanopharmaceuticals (part 1): products on the 944 market. International Journal of Nanomed. 4357-73. DOI 10.2147/IJN.S46900. eCollection 2014

945 Wu D, Si M, Xue HY, Wong HL. 2017. Nanomedicine applications in the treatment of breast 946 cancer: current state of the art. International Journal of Nanomedicine 12:5879-5892. DOI $947 \quad 10.2147 /$ IJN.S123437

948 Wu W, Nan K, Wu E, Chen Y, Zhou J. 2021. Method for creating an animal model having 949 traumatic optical nerve injury (U.S. Patent No. 10,959,412 B2). U.S. Patent and trademark office.

950 Wu W, Nan K, Wu E, Chen Y, Zhou J. 2021. Method for creating an animal model having 951 traumatic optical nerve injury (U.S. Patent No. US 10, 959,412 B2). U.S. Patent trademark office. 
952 Yui N, Ooya T, Sato I. 2004. Chemically modified hyaluronic acid or salts thereof, and a process 953 for producing thereof (U.S. Patent No. US 6,673,919 B2). U.S. Patent and trademark office.

954 Zang L, Hu CMJ, Fang RH, Luk BT, Thamphiwatana SK. 2018. Treating infection by a 955 platelet-targeting microbe using nanoparticles (U.S. Patent No. US 2018/0169027 Al). U.S. Patent 956 trademark office.

957 Zhang C, Fransson M, Zhou Bin. Method for manufacturing carbon nanostructures having 958 minimal surface functional groups (Taiwan Patent No. TW200835647 A).

959 Zhang L, Pang Z, Fang RH, Hu CMJ. 2018. Detoxification using nanoparticles (U.S. Patent No. 960 US 2018/0140558 Al). U.S. Patent trademark office.

961

962

963

964

965

966

Table 1 List of Marketed nanoformulations

967 Table 2 Patent based on nanoformulation

968 Table 3 Details of nanoparticles approved by FDA with their use in treatment of different disease 969 Table 4 Nanoformulations marketed product with their pharmaceutical application.

970

971

972 Figure 1 Demand for nanomedicine in the United States by application, 2013-2025 (USD Billion).

973 Figure 2 Nanomedicine market, by region, 2016 (\%)

974 
Figure 1

Demand for nanomedicine in the United States by application, 2013-2025 (USD Billion)

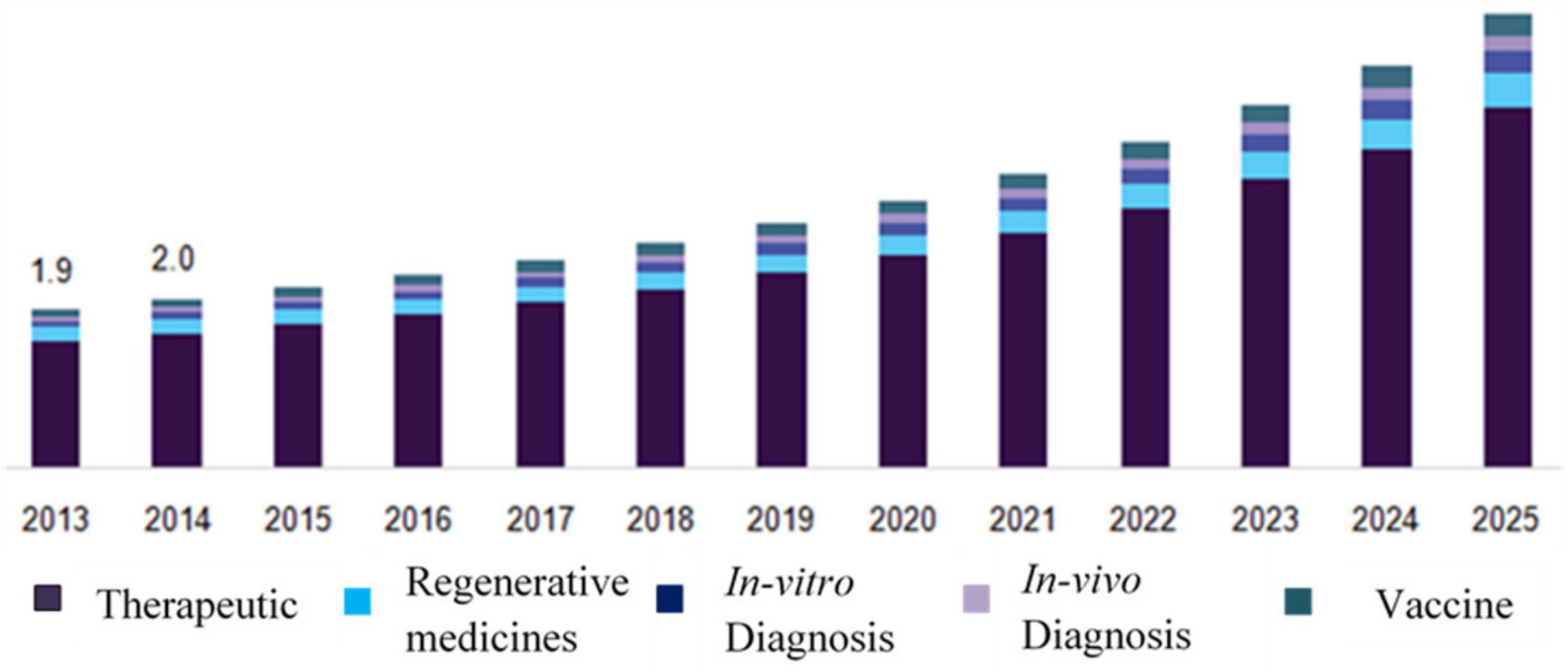




\section{Figure 2}

Nanomedicine market, by region, $2016(\%)$

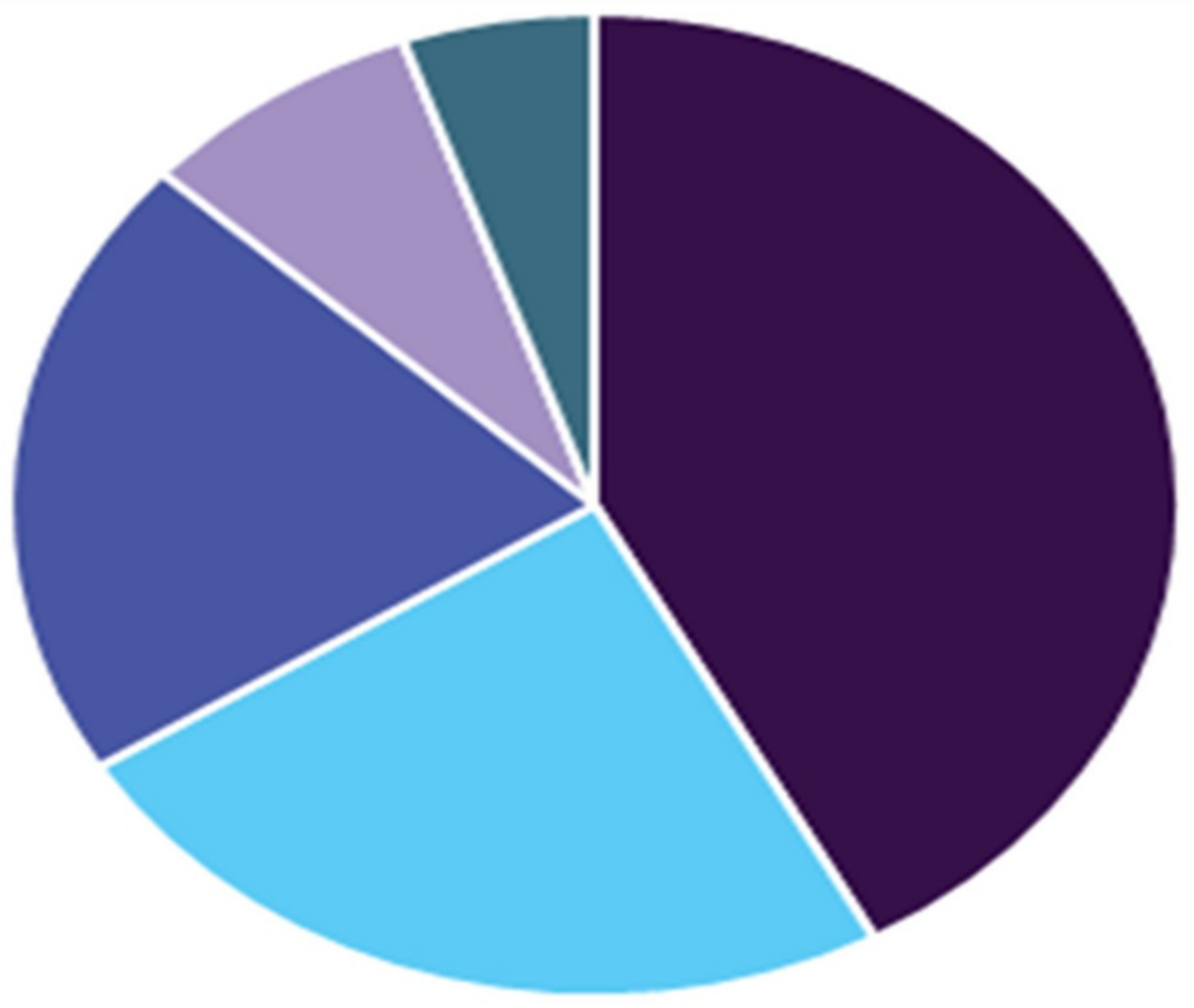

- North America $\square$ Europe $\square$ Asia Pacific $\square$ Latin America $\square$ MEA 
Table $\mathbf{1}$ (on next page)

List of Marketed nanoformulations 
1 Table 1 List of Marketed nanoformulations

\begin{tabular}{|c|c|c|c|}
\hline Formulation & Commercial Name & Active ingredients & Indications \\
\hline Liposomes & $\begin{array}{l}\text { Ambisome } \AA \\
\text { Visudyme }{ }^{\circledR} \\
\text { Abelcet } \AA\end{array}$ & $\begin{array}{l}\text { Amphotericin } \\
\text { Verteporfin } \\
\text { Morphine }\end{array}$ & $\begin{array}{l}\text { Fungal infections } \\
\text { Macular degeneration } \\
\text { Pain reduction }\end{array}$ \\
\hline Pegylated liposome & Caelyx ${ }^{\circledR}$ & Doxorubicin & Cancer \\
\hline Pegylated Liposome & $\begin{array}{l}\text { Cimza } \AA \\
\text { Somavert } \AA\end{array}$ & $\begin{array}{l}\text { Rh-a/b Fab Fragment } \\
\text { against TNF- } \alpha\end{array}$ & Rheumatoid arthritis \\
\hline $\begin{array}{l}\text { Protein drug } \\
\text { conjugate }\end{array}$ & $\begin{array}{l}\text { Kadcyla } \AA \\
\text { Abraxane } \AA\end{array}$ & $\begin{array}{l}\text { Anti-HER2-GI/DM1 } \\
\text { Albumin bound } \\
\text { paclitaxel }\end{array}$ & $\begin{array}{l}\text { HER2- positive breast } \\
\text { cancer }\end{array}$ \\
\hline Nanocrystal & $\begin{array}{l}\text { Lipidic } \AA \\
\text { Rapammune } \AA \\
\text { Emend } \AA\end{array}$ & $\begin{array}{l}\text { Fenofibrate } \\
\text { Sirolimus } \\
\text { Aprepitant }\end{array}$ & $\begin{array}{l}\text { Hypercholesterolameia } \\
\text { Nausea }\end{array}$ \\
\hline Nanosuspension & $\begin{array}{l}\text { Risperadol } \AA \\
\text { Consta } \AA\end{array}$ & Risperidone & Schizophrenia \\
\hline Emulsions & $\begin{array}{l}\text { Neoral } \\
\text { Lipuro }\end{array}$ & $\begin{array}{l}\text { Cyclosporine } \\
\text { Propofol }\end{array}$ & $\begin{array}{l}\text { Immunosuppression } \\
\text { Anaesthesia }\end{array}$ \\
\hline Vaccines & Pandemrix & Split vision & Immunization \\
\hline $\begin{array}{l}\text { Polymeric } \\
\text { Nanoparticles }\end{array}$ & $\begin{array}{l}\text { Renagel } \AA \\
\text { Copaxone } \AA\end{array}$ & $\begin{array}{l}\text { Sevelamer } \\
\text { Glatiramer acetate }\end{array}$ & $\begin{array}{l}\text { Hyperphosphataemia } \\
\text { RR-MS }\end{array}$ \\
\hline
\end{tabular}

2 
Table 2 (on next page)

Table 2

Patent based on nanoformulation 
1 Table 2 Patent based on nanoformulation

\begin{tabular}{|c|c|c|}
\hline S. no. & Inventor name & Work done \\
\hline 1 & $\begin{array}{l}\text { James Q. } \\
\text { Lillard, Jr. } \\
\text { Rajesh Singh }\end{array}$ & $\begin{array}{l}\text { The investigators presented nanoparticles formulation and } \\
\text { methods for supplying a bioactive agent to a plant. Work } \\
\text { highlightd that nanoparticle structure contains a coronatine- } \\
\text { coated nanoparticle that is intended to deliver one or more } \\
\text { bioactive agents via plant stomata. Nanoparticles may include } \\
\text { one or more bactericides, molluscicides, miticides, fungicides, } \\
\text { nemanticides, insecticides, herbicides, acaricides, plant } \\
\text { nutrients, fertilizers, growth regulators, or combinations thereof } \\
\text { (Lillard et al., 2014). }\end{array}$ \\
\hline 2 & Shaker A Mousa & $\begin{array}{l}\text { Wok involves loading of nanoformulation comprising } \\
\text { nanoparticles. In each nanoparticle, a transformed chitosan } \\
\text { polymer encapsulated minimum one vitamin D analog, at least } \\
\text { one vitamin D metabolite, or combinations alike. The changed } \\
\text { chitosan polymer contains chitosan that has been covalently } \\
\text { linked to at least one person was selected from the fatty and } \\
\text { variations respectively. The structure was made up of a solvent } \\
\text { and a nanoformulation, with nanoparticles dispersed in the } \\
\text { medium }(W u \text { et al., 2021). }\end{array}$ \\
\hline 3 & $\begin{array}{l}\text { Anamaria Ioana } \\
\text { Orza }\end{array}$ & $\begin{array}{l}\text { The invention relates to new anti-wrinkle and anti- } \\
\text { aging nanoformulations, composed of non-toxic mesoporous } \\
\text { silica nanoparticles, natural plant extracts (as the case may be: } \\
\text { pomegranate oil, fennel oil, rosemary oil, chamomile oil, jojoba } \\
\text { oil, rosehip oil), biologically active agents (acetyl hexapeptide- } \\
\text { 8, aspartic acid), vitamins and others (Orza, 2017). }\end{array}$ \\
\hline 4 & Vuong Trieu & $\begin{array}{l}\text { The present invention relates to therapeutic agent nanoparticles, } \\
\text { nanoparticle formulations appropriate for injection, means for } \\
\text { administering therapeutic agents and for treating disorders and } \\
\text { conditions treatable by the therapeutic agents using the } \\
\text { formulations, in particular, the formulation and characterization } \\
\text { of nanoparticles containing taxanes such as paclitaxel (Desai et } \\
\text { al., 2009). }\end{array}$ \\
\hline 5 & Vuong Trieu & $\begin{array}{l}\text { The present innovation relates to methods for guiding the } \\
\text { engineering of nanoparticle drugs for intravenous administration } \\
\text { using pharmacokinetic criteria and other studies. The methods of } \\
\text { the present innovation are particularly useful in the preparation } \\
\text { of nanoparticles containing cytotoxic drugs for cancer care (Trie } \\
\text { et al, 2012). }\end{array}$ \\
\hline
\end{tabular}




\begin{tabular}{|c|c|c|}
\hline 6 & $\begin{array}{l}\text { Chiara Nardon } \\
\text { Dolores Fregona } \\
\text { Leonardo } \\
\text { Brustolin } \\
\text { Nicolò } \\
\text { Pettenuzzo }\end{array}$ & $\begin{array}{l}\text { The present development relates to mononuclear coordination } \\
\text { composites of } \mathrm{Au} \text { and } \mathrm{Cu} \text {, pharmaceutical nanoformulations } \\
\text { based thereof, the relative method of synthesis and encapsulation } \\
\text { of the compounds in macromolecules, supramolecular } \\
\text { aggregates, or nanostructures, as well as their use for the } \\
\text { diagnosis and/or treatment of neoplasia (Chiara et al., 2016). }\end{array}$ \\
\hline 7 & $\begin{array}{l}\text { Liangfang } \\
\text { Zhang } \\
\text { Soracha Kun } \\
\text { Thamphiwatana } \\
\text { Che-Ming Jack } \\
\text { Hu Ronnie H. } \\
\text { Fang Brian T. } \\
\text { Luk }\end{array}$ & $\begin{array}{l}\text { The present innovation describes processes, formulations, and } \\
\text { pharmaceutical formulations for preventing and/or treating } \\
\text { infection in a target by a platelet-targeting microbe, utilizing, } \\
\text { among other things, an appropriate volume of a nanoparticle } \\
\text { composed of an inner center, a non-cellular substance, and an } \\
\text { outer surface composed of a cellular membrane extracted from a } \\
\text { platelet (Zhang et al., 2018). }\end{array}$ \\
\hline 8 & $\begin{array}{l}\text { Liangfang } \\
\text { Zhang } \\
\text { Zhiqing Pang } \\
\text { Ronnie H. Fang } \\
\text { Che-Ming Jack } \\
\mathrm{Hu}\end{array}$ & $\begin{array}{l}\text { The current invention pertains to toxin therapy in a patient. The } \\
\text { present invention describes compositions for reducing or } \\
\text { neutralizing the influence of a toxin in a topic by employing, } \\
\text { among other things, an efficient volume of a nanoparticle with } \\
\text { an inner center composed of a non-cellular substance and an } \\
\text { outer surface composed of a cellular membrane obtained from a } \\
\text { source cell. Toxins such as organophosphate overdose are } \\
\text { examples of acetylcholinesterase (AChE) inhibitors (Zhang et } \\
\text { al., 2018). }\end{array}$ \\
\hline 9 & $\begin{array}{l}\text { Rambhau } \\
\text { Devraj, Pranati } \\
\text { Chhatoi, Naga } \\
\text { Hemanth Kumar } \\
\text { Parvathabhatla, } \\
\text { Anand Vasant } \\
\text { Deshmukh, } \\
\text { Krishna Kaushik } \\
\text { Chintabhatla }\end{array}$ & $\begin{array}{l}\text { The present disclosure is geared against a secure nanodispersion } \\
\text { comprised of an aqueous dispersion medium, a dispersed } \\
\text { process, a surface-active agent, and alternatively, an additive, } \\
\text { whereby the aqueous dispersion medium includes a } \\
\text { nanodispersion stabilizing vehicle base portion that enhances the } \\
\text { nanodispersion's long-term physiochemical properties (Devraj et } \\
\text { al., 2015). }\end{array}$ \\
\hline 10 & $\begin{array}{l}\text { Hemanta Koley, } \\
\text { Priyadarshini } \\
\text { Mukherjee, } \\
\text { Dhrubajyoti } \\
\text { Nag, } \\
\text { Ritam Sinha, } \\
\text { Manoj Kumar }\end{array}$ & $\begin{array}{l}\text { An OmpA formulation consisting primarily of a) OmpA protein } \\
\text { as active molecule obtained as a product of the OmpA gene } \\
\text { inserted in a plasmid containing a novel set of forward and } \\
\text { reverse primers and b) Alginate chitosan nanoparticles as a } \\
\text { vehicle (Koley et al., 2019). }\end{array}$ \\
\hline
\end{tabular}




\begin{tabular}{|c|c|c|}
\hline & Chakrabarti & \\
\hline 11 & $\begin{array}{l}\text { Shaker A. } \\
\text { Mousa }\end{array}$ & $\begin{array}{l}\text { Each nanoparticle is encapsulated in a shell that contains sulfated } \\
\text { non-anticoagulant heparin (SNACH), which can be used with } \\
\text { or even without hydrophobic anti-angiogenesis Tyrosine Kinase } \\
\text { inhibitors. The SNACH is ionically or covalently bound to the } \\
\text { shell. In the shell, a polymer from the poly (lactic-co-glycolic } \\
\text { acid) (PLGA), chitosan, chitosan-alginate, and NIPAAM- } \\
\text { APMAH-AA group is included (Mousa, 2017). }\end{array}$ \\
\hline 12 & $\begin{array}{l}\text { Minoru Toriumi } \\
\text { Toshiro Itani }\end{array}$ & $\begin{array}{l}\text { The current innovation describes a tool for planning a composite } \\
\text { near-infrared lasernano formulations triggered by the near- } \\
\text { infrared laser irradiation nanoformulation } 980 \mathrm{~nm} \text {, whereby the } \\
\text { object transmitting means converting the light-triggered } \\
\text { photosensitive nanoparticles release pharmaceutical micelles, to } \\
\text { diagnosis and treatment of visible light through diagnosis and } \\
\text { treatment of secondary medication problem (Toriumi \& Itani, } \\
\text { 2018). }\end{array}$ \\
\hline 13 & $\begin{array}{l}\text { Jiang Hulin } \\
\text { Xing Lei } \\
\text { He Yujing } \\
\text { Cui Pengfei } \\
\text { Huang Wei }\end{array}$ & $\begin{array}{l}\text { The proposed design discloses a type of functional albumin } \\
\text { nanoparticles formulation and preparation method; } \\
\text { functionalized nano-albumin formulation of functional albumin, } \\
\text { a metal ion, and pharmaceutical composition; functional metal } \\
\text { ions simultaneously form a coordinate bond with albumin and } \\
\text { pharmaceutical, inducing self-assembly of nanoparticles (Jiang et } \\
\text { al., 2017). }\end{array}$ \\
\hline 14 & Nan Kaihui & $\begin{array}{l}\text { The innovation relates to a method of preparing a Legumain } \\
\text { sensitive nano preparation for multi-step release of adriamycin } \\
\text { amycin/slow release of curcumin, as well as an operation. A } \\
\text { Legumain sensitive nanogel is prepared based on the biological } \\
\text { feature that tumour tissues transmit Legumain abundantly, } \\
\text { resulting in a double targeting impact (active and passive } \\
\text { targeting) of the tumour tissues and a reduction in secondary } \\
\text { damage on normal tissues caused by adriamycin amycin (Wu et } \\
\text { al., 2021). }\end{array}$ \\
\hline 15 & $\begin{array}{l}\text { Nygaard Halvor } \\
\text { Langmyhr Eyolf }\end{array}$ & $\begin{array}{l}\text { The present discovery discloses a scientific area Scotogramma } \\
\text { belonging to agricultural chemicals prepared armyworm decoy } \\
\text { compositions and formulations become prepared nanoparticles. } \\
\text { The amphiphilic copolymer is shaped by self-assembly in an } \\
\text { aqueous solution with a distinct core-shell framework nano-sized }\end{array}$ \\
\hline
\end{tabular}




\begin{tabular}{|c|c|c|}
\hline & & $\begin{array}{l}\text { micelles, developed by electrospinning technique nanometers } \\
\text { pesticides (Halvor \& Eyolf, 2010). }\end{array}$ \\
\hline 16 & $\begin{array}{lr}\text { Nobuhiko } & \text { Yui } \\
\text { Tooru } & \text { Ooya } \\
\text { Ikuo Sato } & \end{array}$ & $\begin{array}{l}\text { The present discovery is about a procedure and implementation } \\
\text { of a modified hyaluronic acid preparation of single walled carbon } \\
\text { nanotube diagnosis and treatment of drug nanoparticles } \\
\text { sensitivity reducing agent, which can effectively solve the low } \\
\text { targeting anti-cancer drug doxorubicin in tumour (Yui et al., } \\
2004 \text { ). }\end{array}$ \\
\hline 17 & $\begin{array}{l}\text { Martin Hurby } \\
\text { Ingrid } \\
\text { Brezaniova } \\
\text { Vladimir Kral }\end{array}$ & $\begin{array}{l}\text { The invention is directed to photoactivatable nanoparticles for } \\
\text { photodynamic applications that include a photosensitizer, a (C8 } \\
\text { to } \mathrm{C} 22 \text { ) fatty alcohol, and a polymeric surfactant, preferably } \\
\text { poly(ethylene oxide) monomethyl ether-block-poly(eta- } \\
\text { caprolactone), with the size of the nanoparticle ranging from } 1 \text { to } \\
1000 \mathrm{~nm} \text { and the core solid at } 4{ }^{\circ} \mathrm{C} \text {. The present discovery often } \\
\text { applies to a means of producing the photoactivatable } \\
\text { nanoparticle, as well as a medicinal composition comprising it } \\
\text { and its use (Hurby et al., 2019). }\end{array}$ \\
\hline 18 & $\begin{array}{l}\text { Cheng Zhang } \\
\text { Martin Fransson } \\
\text { Bing Zhou }\end{array}$ & $\begin{array}{l}\text { The invention aims to include a nano-carbon preparation for } \\
\text { labeling as well as a tool for making it. The invention's nano- } \\
\text { carbon preparation is increased in dispersibility and consistency, } \\
\text { has good bio-safety, is easy to prepare, has a low manufacturing } \\
\text { cost, and can be used to trace tumour cells in the lymphatic } \\
\text { system and mark lesions or biopsy sites in the digestive tract } \\
\text { (Zhang et al.,). }\end{array}$ \\
\hline 19 & Shaker A Mousa & $\begin{array}{l}\text { This disclosure relates to novel formulations and } \\
\text { Nanoformulations as described in the specification, as well as } \\
\text { formulas containing a mixture of } \mathrm{HCV} \text { protease and polymerase } \\
\text { inhibitors, with or without interferon, as well as anti- } \\
\text { fibrotic/anti-hemolytic agents composed of naturally derived } \\
\text { polyphenols/thiols and non-anticoagulant GAGs. These } \\
\text { compounds are potent antiviral agents, particularly in inhibiting } \\
\text { the function of various genotypes of Hepatitis C virus (HCV) } \\
(\text { Mousa, 2017). }\end{array}$ \\
\hline 20 & $\begin{array}{l}\text { Ana Brotons } \\
\text { Canto } \\
\text { Carlos Gamazo } \\
\text { De La Rasilla }\end{array}$ & $\begin{array}{l}\text { The proposed model discloses nano-formulations for treating } \\
\text { irritable bowel syndrome, as well as by the zein nanoparticles } \\
\text { coated on the outer zein nanoparticles consisting of E. coli outer } \\
\text { membrane vesicles; the zein nanoparticles coated with } \\
\text { antibiotics, antibiotics are antimicrobial peptides; antimicrobial } \\
\text { peptide sequence as a RIVVIRVA, KIWVIRWR, RIWVIRWR, } \\
\text { RIWVIWRR, IWVIRWR, RWVIWRR, VVIRVA, WVIRWR }\end{array}$ \\
\hline
\end{tabular}




\begin{tabular}{|c|c|c|}
\hline & & or in WVIWRR (Canto et al., 2018). \\
\hline 21 & $\begin{array}{l}\text { Shaker } \\
\text { Mousa }\end{array}$ & $\begin{array}{l}\text { Nanoparticles make up a nanoformulation. Each nanoparticle is } \\
\text { encased in a glycosaminoglycan shell (GAG). The GAG is } \\
\text { bound to the shell either ionically or covalently. The GAG is } \\
\text { chosen from among sulfated non-anticoagulant heparin } \\
\text { (SNACH), super-sulfated non-anticoagulant heparin (S- } \\
\text { SNACH), and a combination of the two. The shell is made of } \\
\text { poly (lactic-co-glycolic acid) (PLGA), polyethylene glycol } \\
\text { (PEG)-PLGA, PLGA-Polycaprolate, or calcium alginate. A } \\
\text { technique of utilizing the nanoformulation to manage cancer in a } \\
\text { subject involves prescribing a therapeutically effective volume } \\
\text { of the nanoformulation to the recipient for cancer treatment } \\
\text { (Mousa, 2018). }\end{array}$ \\
\hline 22 & $\begin{array}{ll}\text { Shaker } & \text { A } \\
\text { Mousa, } & \\
\text { Mohammed } & \text { H } \\
\text { Qari, } & \\
\text { Mohammed } & \text { S. } \\
\text { Ardawi } & \end{array}$ & $\begin{array}{l}\text { A nano-composition and a process for using it. The composition } \\
\text { includes nanoparticles. Each nanoparticle has a shell that } \\
\text { contains lycopene. The shell is made up of electrostatically } \\
\text { bound oligomerized (-)-epigallocatechin-3-O-gallate (OEGCG) } \\
\text { to chitosan. The implementation strategy for the formulation } \\
\text { entails delivering the nano-composition to an individual (Mousa } \\
\text { et al., 2017). }\end{array}$ \\
\hline 23 & $\begin{array}{l}\text { Omid C } \\
\text { Farokhzad } \\
\text { Pedro } \\
\text { Valencia } \\
\text { Xiaoyang Xu } \\
\text { Xueging Zhang } \\
\text { Mingming Ma } \\
\text { Nazila Kamaly }\end{array}$ & $\begin{array}{l}\text { The four major components of sub-100 micron multimodal } \\
\text { nanoparticles are: 1) A target factor that can attach to cells, } \\
\text { tissues, or organs of the body selectively; 2) A diagnostic agent, } \\
\text { such as a fluorophore or NMR contrast agent, that allows } \\
\text { nanoparticles to be visualized at the site of delivery 3) An outer } \\
\text { "stealth" coating that enables the particles to avoid detection by } \\
\text { immune system components; and 4) a biodegradable polymeric } \\
\text { substance that forms an inner center capable of carrying } \\
\text { therapeutics and releasing payloads at a sustained pace during } \\
\text { systemic, intraperitoneal, or mucosal administration (Farokhzad } \\
\text { et al., 2013). }\end{array}$ \\
\hline 24 & $\begin{array}{l}\text { Shaker } \\
\text { Mousa }\end{array}$ & $\begin{array}{l}\text { A nanoparticle-containing nano-composition, a method of } \\
\text { forming the nano-composition, and a method of using the } \\
\text { composition are all described. Chitosan, poly L-Lysine, poly L- } \\
\text { Arginine, methylated chitosan, are polycationic polymers that } \\
\text { are ionically attached to one or more polyanionic } \\
\text { Glycosaminoglycans (GAGs) (Davis et al., 2010). }\end{array}$ \\
\hline 25 & $\begin{array}{l}\text { Wang Xuemei } \\
\text { Zhao Chunqiu } \\
\text { Wang Jianling }\end{array}$ & $\begin{array}{l}\text { The present discovery discloses a nanocomposite porphyrin } \\
\text { derivative of nanoformulation for use in photodynamic therapy } \\
\text { and photothermal therapy for rheumatoid arthritis, as well as it's }\end{array}$ \\
\hline
\end{tabular}




\begin{tabular}{|l|l} 
Ren Fa & use (Wang et al., 2017).
\end{tabular}

2 


\section{Table 3(on next page)}

Table 3

Details of nanoparticles approved by FDA with their use in treatment of different disease 
1 Table 3 Details of nanoparticles approved by FDA with their use in treatment of different disease.

\begin{tabular}{|c|c|c|}
\hline S. No. & Nanoparticles type/drug & Application \\
\hline 1. & Iron dextran colloid & $\begin{array}{l}\text { Iron deficient anemia (Anselmo \& Mitragotri, } \\
\text { 2019) }\end{array}$ \\
\hline 2. & Liposomal verteporfin & $\begin{array}{l}\text { Mascular degeneration (Anselmo \& Mitragotri, } \\
\text { 2019) }\end{array}$ \\
\hline 3. & Liposomal amphotericin B & $\begin{array}{l}\text { Treatment and prevention of invasive fungal } \\
\text { infection (Anselmo \& Mitragotri, 2019) }\end{array}$ \\
\hline 4. & Liposomal propofol & $\begin{array}{l}\text { General anesthesia in open heart surgery or spinal } \\
\text { surgery, morbidly obese patient (Anselmo \& } \\
\text { Mitragotri, 2019) }\end{array}$ \\
\hline 5. & Perflutren lipid microspheres & $\begin{array}{l}\text { Ultrasound contrast agent (Anselmo \& Mitragotri, } \\
\text { 2019) }\end{array}$ \\
\hline 6. & Iron carboxymaltose colloid & $\begin{array}{l}\text { Iron deficient anemia (Anselmo \& Mitragotri, } \\
\text { 2019) }\end{array}$ \\
\hline 7. & Iron gluconate colloid & $\begin{array}{l}\text { Iron deficient anemia (Anselmo \& Mitragotri, } \\
\text { 2019) }\end{array}$ \\
\hline 8. & Iron sucrose colloid & $\begin{array}{l}\text { Iron deficient anemia following autologous stem } \\
\text { cell transplantation (Anselmo \& Mitragotri, 2019) }\end{array}$ \\
\hline 9. & $\begin{array}{l}\text { Iron polyglucose } \\
\text { carboxymethylether colloid }\end{array}$ & $\begin{array}{l}\text { Iron deficient anemia following chronic kidney } \\
\text { disease (Anselmo \& Mitragotri, 2019) }\end{array}$ \\
\hline 10. & Liposomal doxorubicin & $\begin{array}{l}\text { Solid malignancies, pancreatic, breast, ovarian, } \\
\text { leukemia, prostate, liver and metastatic cancer, } \\
\text { Kaposi's sarcoma myeloma (Anselmo \& } \\
\text { Mitragotri, 2019) }\end{array}$ \\
\hline 11. & Liposomal daunorubicin & $\begin{array}{l}\text { Various leukemias, Kaposi's sarcoma (Anselmo \& } \\
\text { Mitragotri, 2019), (Obeid, 2018) }\end{array}$ \\
\hline 12. & $\begin{array}{l}\text { Albumin-particle } \\
\text { paclitaxel }\end{array}$ & $\begin{array}{l}\text { Solid malignancies, lymphomas, breast, bladder, } \\
\text { lung, neck and head, pancreatic, ovarian, prostate, } \\
\text { liver and melanoma (Anselmo \& Mitragotri, 2019) }\end{array}$ \\
\hline 13. & Liposomal vincristin & $\begin{array}{l}\text { Brain, lymphomas, melanoma and leukemia } \\
\text { (Anselmo \& Mitragotri, 2019), (Obeid, 2018) }\end{array}$ \\
\hline 14. & Liposomal irinotecan & $\begin{array}{l}\text { Solid malignancies, pancreatic, breast, brain or } \\
\text { sarcomas cancer (Anselmo \& Mitragotri, 2019) }\end{array}$ \\
\hline 11. & $\begin{array}{l}\text { Cytarabine:daunorubicin } \\
\text { liposomal formulation }\end{array}$ & Different leukemias (Anselmo \& Mitragotri, 2019) \\
\hline 12. & RNAi lipid protein & $\begin{array}{l}\text { Transthyretin mediated amyloidosis (Anselmo \& } \\
\text { Mitragotri, 2019) }\end{array}$ \\
\hline 13. & Albumin bound Paclitaxel & $\begin{array}{l}\text { Metastatic breast cancer, lung cancer (Obeid, } \\
\text { 2018), (Desai,2006) }\end{array}$ \\
\hline
\end{tabular}




\begin{tabular}{|l|l|l|}
\hline 14. & Liposomal cytarabine & $\begin{array}{l}\text { Malignant lymphomatous meningitis (Obeid, } \\
2018),(\text { Desai,2006 })\end{array}$ \\
\hline 15. & Paclitaxel polymeric micelle & $\begin{array}{l}\text { Cell lung and breast cancer (Obeid, 2018), } \\
(\text { Desai,2006 })\end{array}$ \\
\hline
\end{tabular}

2 


\section{Table 4 (on next page)}

\section{Table 4}

Nanoformulations marketed product with their pharmaceutical application 
1 Table 4 Nanoformulations marketed product with their pharmaceutical application.

\begin{tabular}{|c|c|c|}
\hline S. No. & $\begin{array}{l}\text { Nanoformulations } \quad \text { marketed } \\
\text { products }\end{array}$ & Pharmaceutical application \\
\hline 1. & Rapamune $^{\circledR}$ & $\begin{array}{l}\text { Immunosuppressant (Kalepu \& Nekkanti, } \\
\text { 2015) }\end{array}$ \\
\hline 2. & Tricor $^{\circledR}$ & $\begin{array}{l}\text { Hypercholesterolemia (Kalepu \& Nekkanti, } \\
\text { 2015) }\end{array}$ \\
\hline 3. & Emend $^{\circledR}$ & $\begin{array}{l}\text { Anti-emetic (Kalepu \& Nekkanti, 2015), } \\
\text { (Bharali et al., 2011) }\end{array}$ \\
\hline 4. & Megace ES ${ }^{\circledR}$ & Anti-anorexic (Kalepu \& Nekkanti, 2015) \\
\hline 5. & Avinza $^{\circledR}$ & $\begin{array}{l}\text { Phychostimulant drug (Kalepu \& Nekkanti, } \\
\text { 2015) }\end{array}$ \\
\hline 6. & Triglide $^{\circledR}$ & $\begin{array}{l}\text { Hypercholesterolemia (Kalepu \& Nekkanti, } \\
\text { 2015) }\end{array}$ \\
\hline 7. & Focalin $^{\circledR}$ & $\begin{array}{l}\text { Attention deficit hyperactivity disorder } \\
\text { (Kalepu \& Nekkanti, 2015) }\end{array}$ \\
\hline 8. & Ritalin $^{\circledR}$ & CNS stimulant (Kalepu \& Nekkanti, 2015) \\
\hline 9. & Daunoxome $^{\circledR}$ & $\begin{array}{l}\text { Anti-cancer (Lohcharoenkal et al., 2014), } \\
\text { (Bharali et al., 2011) }\end{array}$ \\
\hline 10. & Myocet $^{\circledR}$ & Anti-cancer \\
\hline 11. & Doxil $^{\circledR}$ & $\begin{array}{l}\text { Anti-cancer, Antiretroviral (Lohcharoenkal } \\
\text { et al., 2014), (Bharali et al., 2011) }\end{array}$ \\
\hline 12. & Caelyx $^{\circledR}$ & Anti-cancer (Lohcharoenkal et al., 2014) \\
\hline 13. & Genexol-PM $^{\circledR}$ & Anti-cancer (Lohcharoenkal et al., 2014) \\
\hline 14. & Transdrug $^{\circledR}$ & Anti-cancer (Lohcharoenkal et al., 2014) \\
\hline 15. & Abraxane $^{\circledR}$ & $\begin{array}{l}\text { Anti-cancer (Lohcharoenkal et al., 2014), } \\
\text { (Bharali et al., 2011) }\end{array}$ \\
\hline 16. & Oncaspar ${ }^{\circledR}$ & $\begin{array}{l}\text { Anti-cancer (Lohcharoenkal et al., 2014), } \\
\text { (Bharali et al., 2011) }\end{array}$ \\
\hline 17. & Combidex $^{\circledR}$ & Anti-cancer (Bharali et al., 2011) \\
\hline 18. & Endorem $^{\circledR}$ & MRI contrast agents (Maximilien, 2015) \\
\hline 19. & Feridex $^{\circledR}$ & MRI contrast agents (Maximilien, 2015) \\
\hline 20. & Ontak $^{\circledR}$ & Non-Hodgkin lymphoma (Maximilien, 2015) \\
\hline 21. & Feraheme ${ }^{\circledR}$ & Anti-anaemic (Maximilien, 2015) \\
\hline 22. & Marqibo $^{\circledR}$ & Anti-cancer (Maximilien, 2015) \\
\hline 23. & Docetaxel PNP ${ }^{\circledR}$ & Anti-tumor (Maximilien, 2015) \\
\hline
\end{tabular}

